\title{
Surface Analysis of Carbon Steel Protected from Corrosion by a New Ternary Inhibitor Formulation Containing Phosphonated Glycine, $\mathrm{Zn}^{2+}$ and Citrate
}

\author{
Boyapati Venkata Appa Rao', Madala Venkateswara Rao $^{2}$, Sirugudu Srinivasa Rao ${ }^{3 *}$, Bojja Sreedhar \\ ${ }^{1}$ Department of Chemistry, National Institute of Technology, Warangal, India; ${ }^{2}$ Department of Chemistry, Andhra Loyola College, \\ Vijayawada, India; ${ }^{3}$ Department of Chemistry, V. R. Siddhartha Engineering College, Vijyawada, India; ${ }^{4}$ Inorganic \& Physical \\ Chemistry Division, Indian Institute of Chemical Technology, Hyderabad, India. \\ Email: *chemysri@yahoo.com
}

Received November $29^{\text {th }}, 2012$; revised December $30^{\text {th }}, 2012$; accepted January $5^{\text {th }}, 2013$

\begin{abstract}
Studies on surface analysis of carbon steel protected from corrosion in low chloride and nearly neutral aqueous environment by a synergistic mixture containing N,N-bis(phosphonomethyl) glycine (BPMG), zinc ions and citrate ions are presented. The effect of addition of citrate to the binary system, BPMG- $\mathrm{Zn}^{2+}$, is quite significant and is well explored through various studies. The surface protective nature is maintained in the $\mathrm{pH}$ range $5-9$. Potentiodynamic polarization studies inferred that the ternary inhibitor is a mixed inhibitor. Impedance studies of the metal/solution interface indicated that the surface film is highly protective against the corrosion of carbon steel in the chosen environment. X-ray photoelectron spectroscopic (XPS) analysis of the surface film showed the presence of the elements namely iron, phosphorus, nitrogen, carbon, oxygen and zinc. Deconvolution spectra of these elements in the surface film inferred the presence of oxides/hydroxides of iron(III), $\mathrm{Zn}(\mathrm{OH})_{2}$ and [Fe(III), $\mathrm{Zn}(\mathrm{II})-\mathrm{BPMG}$-citrate] heteropolynuclear multiligand complex. This inference is further supported by the reflection absorption Fourier transform infrared spectrum of the surface film. Analysis by scanning electron microscopy (SEM) is presented for both the corroded and protected metal surfaces. Based on all these results, a plausible mechanism of corrosion inhibition is proposed.
\end{abstract}

Keywords: Carbon Steel; Corrosion Inhibitor; Protective Film; Synergism; BPMG; Citrate

\section{Introduction}

Application of inhibitors is a widely used method for corrosion control of carbon steel, the primary material used in the construction of cooling water systems and other industrial water distribution systems. Due to environmental restrictions imposed on heavy metal ion based corrosion inhibitors, the focus has been shifted to environmentally friendly corrosion inhibitors [1]. Phosphonate-based formulations are well-known for corrosion inhibition of carbon steel [2-12] and the impact of phosphonic acids on environment was reported to be negligible at the concentration levels used for corrosion inhibittion $[13,14]$. Phosphonic acids show synergistic effect with zinc ions and form complexes [1,4-6,9,10]. A phosphonated aminoacid namely N,N-bis (phosphonomethyl) glycine (BPMG), was reported to be an environmentally friendly compound and also an effective corrosion inhibitor in combination with metal ions like $\mathrm{Zn}^{2+}[12,15]$. BPMG is also known to form complexes with metal ions

\footnotetext{
Corresponding author.
}

like $\mathrm{Fe}^{2+}, \mathrm{Fe}^{3+}, \mathrm{Zn}^{2+}$, etc. [16]. In order to develop the inhibitor formulation containing relatively low concentration of BPMG, addition of one more synergist to the binary system, BPMG- $\mathrm{Zn}^{2+}$, has been thought of in the present study. For this purpose, an environmentally friendly organic compound namely trisodium citrate was chosen as the second synergist for the following reasons. It consists of three carboxylic acid groups and one hydroxyl group. Citrate can form complexes with metal ions like $\mathrm{Fe}^{2+}, \mathrm{Fe}^{3+}, \mathrm{Zn}^{2+}$, etc. [17-19]. The objectives of the present study are to investigate the inhibitive properties of the surface film formed by the ternary inhibitor system, BPMG- $\mathrm{Zn}^{2+}$-citrate on carbon steel in the presence of chloride and nearly neutral aqueous environment using electrochemical and surface analytical techniques and to discuss the mechanistic aspects of corrosion inhibition. For all these studies, $200 \mathrm{ppm}$ of sodium chloride solution has been chosen as control because of the following reason. Water used in cooling water systems is generally either demineralized water or unpolluted surface water. In either case, the aggressiveness of the water 
does not normally exceed that of $200 \mathrm{ppm}$ of $\mathrm{NaCl}$ solution.

\section{Experimental Section}

\subsection{Materials}

For all the studies, the specimens taken from a single sheet of carbon steel of the following composition were chosen: C: $0.1 \%-0.2 \%$, P: $0.03 \%-0.08 \%$, S: $0.02 \%-$ $0.03 \%, \mathrm{Mn}: 0.4 \%-0.5 \%$ and the rest iron. Prior to the tests, the specimens were polished to mirror finish with $1 / 0,2 / 0,3 / 0$ and $4 / 0$ grade emery polishing papers respectively, washed with distilled water, degreased with acetone and dried. For gravimetric measurements, the polished specimens of the dimensions, $3.5 \mathrm{~cm} \times 1.5 \mathrm{~cm} \times$ $0.2 \mathrm{~cm}$, were used while for electrochemical and surface analytical studies, the dimensions of the specimens were $1.0 \mathrm{~cm} \times 1.0 \mathrm{~cm} \times 0.1 \mathrm{~cm}$. Electrochemical studies were carried out at an optimum immersion period of $1 \mathrm{~h}$ and for the surface analytical studies, the immersion period is 7 days. N,N-bis(phosphonomethyl) glycine (BPMG) obtained from Aldrich Chemical Company Inc., USA, was used as such in the present study. Trisodium citrate $\left(\mathrm{Na}_{3} \mathrm{C}_{6} \mathrm{H}_{5} \mathrm{O}_{7} \cdot 2 \mathrm{H}_{2} \mathrm{O}\right)$, zinc sulphate $\left(\mathrm{ZnSO}_{4} \cdot 7 \mathrm{H}_{2} \mathrm{O}\right)$, sodium chloride and other reagents were analytical grade chemicals. The molecular structures of BPMG and trisodium citrate are shown in Figures $\mathbf{1}$ and $\mathbf{2}$ respectively. All the solutions were prepared using triple distilled nondeaerated water. $\mathrm{pH}$ values of the solutions were adjusted using $0.01 \mathrm{~N} \mathrm{NaOH}$ and $0.01 \mathrm{~N} \mathrm{H}_{2} \mathrm{SO}_{4}$ solutions. An aqueous solution consisting of $200 \mathrm{ppm}$ of sodium chloride has been used as the control throughout the study.

\subsection{Gravimetric Measurements}

For all the gravimetric experiments, the polished specimens were weighed and immersed in duplicate, in 100

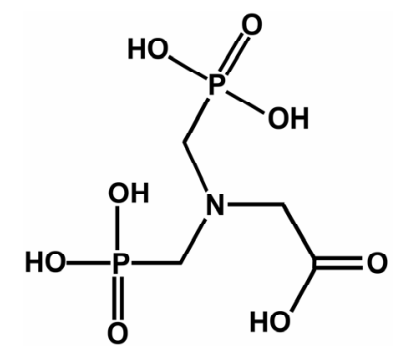

Figure 1. Molecular structure of BPMG.<smiles>[NH3+][18O]CC(O)(CC(=O)O[Na])C(=O)O[Na]</smiles>

Figure 2. Molecular structure of Trisodium citrate.
$\mathrm{mL}$ control solution in the absence and presence of inhibitor formulations of different concentrations, for a period of seven days. Then the specimens were reweighed after washing, degreasing and drying. During the studies, only those results were taken into consideration, in which the difference in the weight-loss of the two specimens immersed in the same solution did not exceed $0.1 \mathrm{mg}$. Accuracy in weighing up to $0.01 \mathrm{mg}$ and in surface area measured up to $0.1 \mathrm{~cm}^{2}$, as recommended by ASTM G31, was followed [20]. The immersion period of seven days was fixed in view of the considerable magnitude of the corrosion rate obtained in the absence of any inhibitor after this immersion period. The immersion period was maintained accurately up to $0.1 \mathrm{~h}$ in view of the lengthy immersion period of $168 \mathrm{~h}$. Under these conditions of accuracy, the relative standard error in corrosion rate determination is of the order of $2 \%$ or less for an immersion time of $168 \mathrm{~h}$ [21]. Inhibition efficiency values $\left(\mathrm{IE}_{\mathrm{g}}\right)$ of the inhibitor formulations were calculated using the formula,

$$
\mathrm{IE}_{\mathrm{g}}(\%)=100\left[(\mathrm{CR})_{\mathrm{O}}-(\mathrm{CR})_{\mathrm{I}}\right] /(\mathrm{CR})_{\mathrm{O}}
$$

where $(\mathrm{CR})_{\mathrm{O}}$ and $(\mathrm{CR})_{\mathrm{I}}$ are the corrosion rates in the absence and presence of inhibitor respectively.

Gravimeric studies were carried out on the ternary system containing BPMG (20 - $30 \mathrm{ppm}), \mathrm{Zn}^{2+}(20-40$ ppm) and citrate $(0-200 \mathrm{ppm})$ to establish minimum concentrations of both BPMG and $\mathrm{Zn}^{2+}$ in presence of citrate for effective inhibition. The selected concentrations of BPMG and $\mathrm{Zn}^{2+}$ for the ternary formulation are based on previous study reported in literature [15]. During these studies, the inhibition efficiencies of citrate alone and of BPMG-citrate combination were also determined. The effect of $\mathrm{pH}$ on inhibition efficiency was determined in case of the effective ternary inhibitor formulations.

\subsection{Electrochemical Studies}

Both the electrochemical impedance spectroscopic (EIS) studies and potentiodynamic polarization studies were carried out using Electrochemical Workstation Model IM6e Zahner-electrik, GmbH, Germany and the experimental data were analysed by using the Thales software. The measurements were conducted in a conventional three-electrode cylindrical glass cell with platinum electrode as auxiliary electrode and Saturated Calomel Electrode (SCE) as reference electrode. The working electrode was carbon steel embedded in epoxy resin of polytetrafluoroethylene so that the flat surface of $1 \mathrm{~cm}^{2}$ was the only surface exposed to the electrolyte. The three-electrode set up was immersed in control solution of volume $500 \mathrm{~mL}$ both in the absence and presence of 
various inhibitor formulations and allowed to attain a stable open circuit potential (OCP). The $\mathrm{pH}$ values of the solutions were adjusted to 7.0 and the solutions were unstirred during the measurements.

Polarization curves were recorded in the potential range of -650 to $-150 \mathrm{mV}$ with a resolution of $2 \mathrm{mV}$. The curves were recorded in the dynamic scan mode with a scan rate of $2 \mathrm{mV} / \mathrm{s}$. The ohmic drop compensation has been made during the studies. The corrosion potential $\left(\mathrm{E}_{\text {corr }}\right)$, corrosion current density $\left(\mathrm{I}_{\text {corr }}\right)$ and anodic Tafel slope $\left(\beta_{\mathrm{a}}\right)$ and cathodic Tafel slope $\left(\beta_{\mathrm{c}}\right)$ were obtained by extrapolation of anodic and cathodic regions of the Tafel plots. The inhibition efficiency values $\left(\mathrm{IE}_{\mathrm{p}}\right)$ were calculated from $\mathrm{I}_{\text {corr }}$ values using the equation [22],

$$
\operatorname{IE}_{\mathrm{p}}(\%)=100\left[1-\left(\mathrm{i}_{\text {corr }}^{\prime} / \mathrm{i}_{\text {corr }}\right)\right]
$$

where $i_{\text {corr }}$ and $i_{\text {corr }}^{\prime}$ are the corrosion current densities in case of the control and inhibitor solutions respectively.

Impedance spectra in the form of Nyquist plots were recorded at OCP in the frequency range from $60 \mathrm{kHz}$ to $10 \mathrm{mHz}$ with 4 to 10 steps per decade. A sine wave, with $10 \mathrm{mV}$ amplitude, was used to perturb the system. The impedance parameters viz. charge transfer resistance $\left(\mathrm{R}_{\mathrm{ct}}\right)$, constant phase element (CPE) and CPE exponent (n) were obtained from Nyquist plots. The inhibition efficiency values $\left(\mathrm{IE}_{\mathrm{i}}\right)$ were calculated using the equation,

$$
\mathrm{IE}_{\mathrm{i}}(\%)=100\left[1-\left(\mathrm{R}_{\mathrm{ct}} / \mathrm{R}_{\mathrm{ct}}^{\prime}\right)\right]
$$

where $R_{c t}$ and $R_{c t}^{\prime}$ are the charge transfer resistance values in the absence and presence of the inhibitor respectively.

\subsection{Surface Analysis by X-Ray Photoelectron Spectroscopy (XPS)}

XPS measurements of the surface films were carried out with Kratos analytical photoelectron spectrometer model AXIS 165 with monochromated $\mathrm{Al} \mathrm{K}_{\alpha} \mathrm{X}$-ray source $(1486.6 \mathrm{eV})$ operated at $100 \mathrm{~W}$ and with a resolution of $0.1 \mathrm{eV}$. Both the survey spectra and deconvolution spectra were recorded at four spots on each specimen. The average of the four measurements is reported. The spectra were collected at an electron take-off angle of $90^{\circ}$. Analyser pass energy was $80 \mathrm{eV}$, with a step of $0.1 \mathrm{eV}$ for the elements of interest namely Fe 2p, P 2p, N 1s, C $1 \mathrm{~s}, \mathrm{O} 1 \mathrm{~s}$ and $\mathrm{Zn} 2 \mathrm{p}$. Binding energies for the deconvolution spectra were corrected individually for each measurement set, based on a value of $285.0 \mathrm{eV}$ for the C-C component of $\mathrm{C} 1 \mathrm{~s}$.

\subsection{Fourier Transform Infrared Spectroscopic Studies (FTIR)}

FTIR spectra were recorded using FTIR spectropho- tometer from Thermo Electron Corporation, USA, model Nexus 670 with a resolving power of $0.125 \mathrm{~cm}^{-1}$. The detector is temperature stabilised DTGS ( $\mathrm{KBr}$ window) and liquid nitrogen cooled MCT-A and the beam splitter is XT-KBr. FTIR spectrum of pure BPMG and pure trisodium citrate were recorded using $\mathrm{KBr}$ pellet method. The reflection absorption FTIR spectra of the surface films were recorded in the wave number range of 4000 $400 \mathrm{~cm}^{-1}$. The measurements were made at a grazing angle of $85^{\circ}$.

\subsection{Surface Analysis by Scanning Electron Microscopy (SEM)}

SEM images were recorded using FEI Quanta FEG 200 High Resolution Scanning Electron Microscope for the specimens immersed in the control as well as in the inhibitor solution at two different magnifications.

\section{Results and Discussion}

\subsection{Gravimetric Studies}

Figure 3 presents the results of gravimetric studies of citrate alone as an inhibitor. The inhibition efficiency increases gradually with increase in concentration of citrate, reaches the highest value of only $43 \%$ at $350 \mathrm{ppm}$ and gets reduced upon further increase of citrate concentration up to $500 \mathrm{ppm}$. Thus, citrate alone does not function as an effective inhibitor even at higher concentrations. Results of several studies on the binary system consisting of BPMG and citrate ions (in the absence of $\mathrm{Zn}^{2+}$ ) proved that this combination does not show any inhibition efficiency at different compositions of mixtures of BPMG and citrate ions in the concentration range $20-200 \mathrm{ppm}$ (results of these studies are not presented here). On the other hand reports [23] are available that mixtures of $\mathrm{Zn}^{2+}$ and citrate ions at relatively higher concentrations of both offer some inhibition efficiency, which is far less than the inhibition efficiency obtained by the mixture of BPMG and $\mathrm{Zn}^{2+}$ at comparable concentrations.

Figure 4 shows the inhibition efficiency of the ternary system, BPMG- $\mathrm{Zn}^{2+}$-citrate, as a function of concentration of citrate at different concentrations of BPMG and $\mathrm{Zn}^{2+}$. From the figure, it can be observed that in case of all these ternary formulations at $\mathrm{pH} 7$, as the concentration of citrate is increased, the inhibition efficiency increases, reaches a maximum at an optimum concentration of citrate and then decreases. In order to achieve an inhibition efficiency $>90 \%$, the required minimum concentrations of BPMG and $\mathrm{Zn}^{2+}$ are $20 \mathrm{ppm}$ and $30 \mathrm{ppm}$ respectively in presence of citrate. While the binary system consisting of $20 \mathrm{ppm}$ BPMG and $30 \mathrm{ppm} \mathrm{Zn}^{2+}$ accelerates corrosion, with the addition of $100 \mathrm{ppm}$ of cit- 


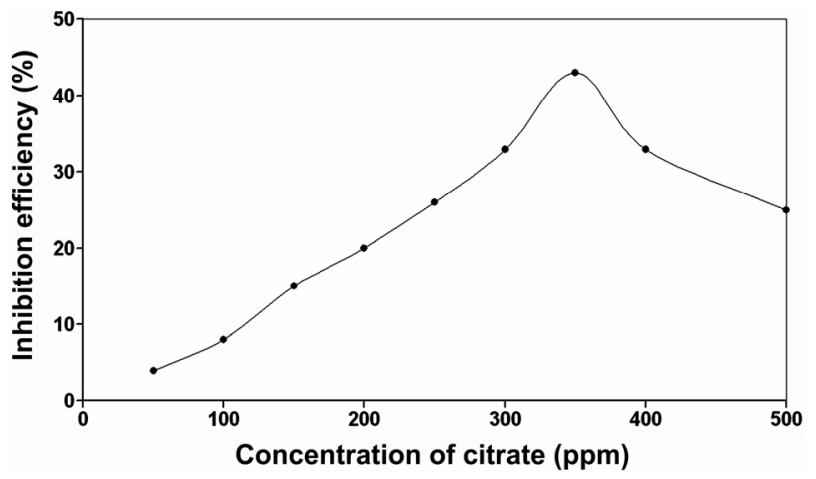

Figure 3. Corrosion inhibition efficiency of citrate alone.

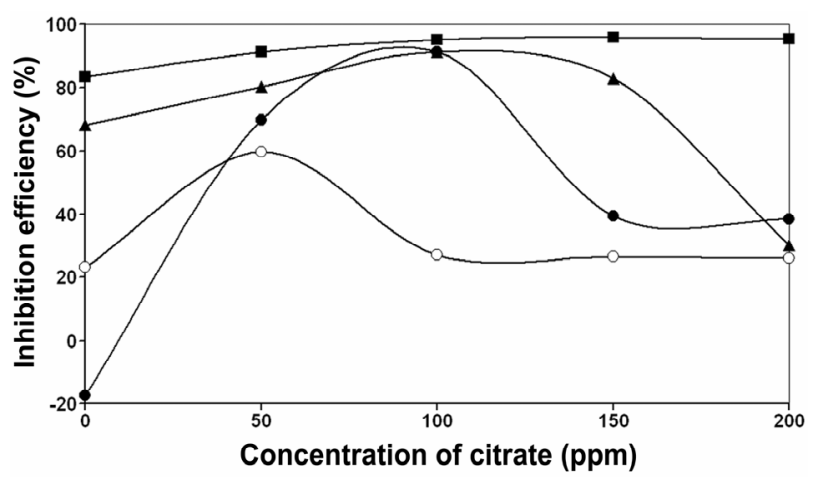

Figure 4. Corrosion inhibition efficiency of the ternary inhibitor formulations containing BPMG, $\mathrm{Zn}^{2+}$ and citrate as a function of concentration of citrate $\rightarrow$ BPMG (20 ppm) $+\mathrm{Zn}^{2+}(30 \mathrm{ppm})+$ citrate; $\rightarrow$ BPMG (30 ppm) + $\mathrm{Zn}^{2+}(20 \mathrm{ppm})+$ citrate; - BPMG (30 ppm) $+\mathrm{Zn}^{2+}(30$ ppm) + citrate; - - BPMG $(30 \mathrm{ppm})+\mathrm{Zn}^{2+}(40 \mathrm{ppm})+$ citrate.

rate, the inhibition efficiency of the ternary formulation is $91 \%$. Further increase in the concentration of citrate ions, say to $150 \mathrm{ppm}$ and $200 \mathrm{ppm}$ reduced the inhibition efficiency to $39 \%$. In case of the binary system containing $30 \mathrm{ppm}$ each of BPMG and $\mathrm{Zn}^{2+}$, the inhibition efficiency is $68 \%$, which is increased to $91 \%$ by the addition of $100 \mathrm{ppm}$ of citrate. On further increase in the concentration of citrate, say to $150 \mathrm{ppm}$ and $200 \mathrm{ppm}$, the inhibition efficiency is reduced to $82 \%$ and $30 \%$ respectively. When the binary system containing $30 \mathrm{ppm}$ BPMG and $40 \mathrm{ppm} \mathrm{Zn}^{2+}$ is considered, the observed inhibition efficiency is $83 \%$, which is increased to $91 \%$ by the addition of $50 \mathrm{ppm}$ of citrate and at higher concentrations of citrate from $100-200 \mathrm{ppm}$, the inhibition efficiency is $95 \%$. From these results, an observation is made as follows. When the concentrations of $\mathrm{Zn}^{2+}$ ions and/or BPMG are lower, an increase in the concentration of citrate up to $100 \mathrm{ppm}$ increases the inhibition efficiency and when the concentration of citrate ions is greater than $100 \mathrm{ppm}$, say $150 \mathrm{ppm}$ or $200 \mathrm{ppm}$, there is a drastic decrease in inhibition efficiency. This can be explained as follows. In case of the ternary system consisting of BPMG, $\mathrm{Zn}^{2+}$ and citrate, the system containing optimum concentration of each of the components gives the highest inhibition efficiency. In other words, optimum amounts of each of the three components must be adsorbed on the surface of the metal, so that each one of them plays its own role in formation of protective film either through complex formation or through formation of $\mathrm{Zn}(\mathrm{OH})_{2}$ on cathodic sites, covering the entire metal surface. At higher concentrations of citrate ions viz., $150 \mathrm{ppm}$ and above in the bulk, more citrate is reaching the surface of the metal at the cost of the required optimum concentrations of BPMG and $\mathrm{Zn}^{2+}$ on the surface and therefore the necessary optimum concentrations of $\mathrm{BPMG}$ and $\mathrm{Zn}^{2+}$ required for the formation of protective film, is not available on the surface. Hence the observed decrease in the inhibition efficiency of the ternary system at concentrations of citrate ions $\geq 150 \mathrm{ppm}$. It may be mentioned here that the molar ratio of BPMG: $\mathrm{Zn}^{2+}:$ citrate is 1:6.3:7 to exhibit excellent synergism. The role of each synergist is explained under mechanistic aspects of corrosion inhibition later in this paper.

The influence of $\mathrm{pH}$ on the inhibition efficiency values of various compositions of the ternary system, BPMG$\mathrm{Zn}^{2+}$-citrate, in the $\mathrm{pH}$ range, 4.0 to 9.0 is shown in Figure 5. No adverse effect on the inhibition efficiency is observed with a decrease of $\mathrm{pH}$ from neutral to acidic i.e. from $\mathrm{pH} 7.0$ to 5.0 when the concentrations of citrate ions are low say at $50 \mathrm{ppm}$ and $100 \mathrm{ppm}$. A slight decrease in the inhibition efficiency both at $\mathrm{pH} 6.0$ and $\mathrm{pH}$ 5.0 is observed, when the citrate concentration is greater than $100 \mathrm{ppm}$. When the $\mathrm{pH}$ is increased from neutral to

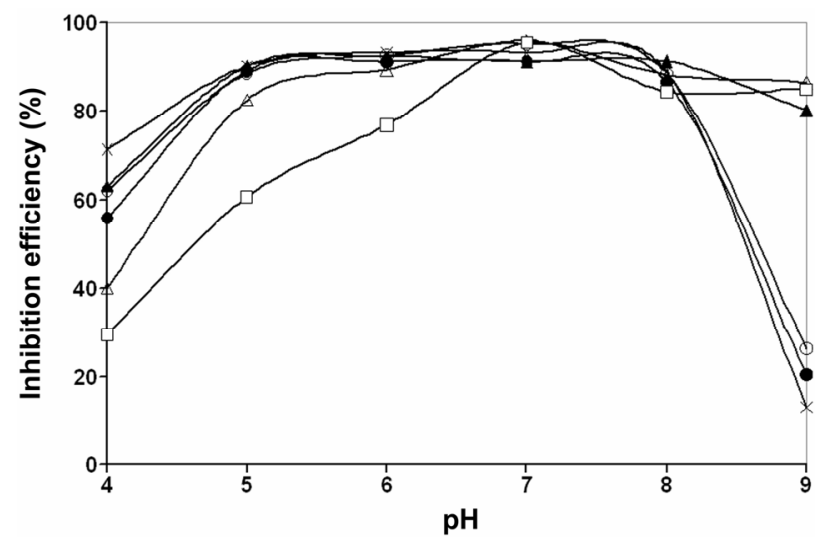

Figure 5. Corrosion inhibition efficiencies of the ternary inhibitor formulations as a function of $\mathrm{pH}$ (numbers in brackets indicate concentrations in ppm units) $\rightarrow-$ BPMG (20) + $\mathrm{Zn}^{2+}$ (30) + citrate (100); - BPMG (30) $+\mathrm{Zn}^{2+}(30)+$ citrate (100); $\longrightarrow$ BPMG (30) $+\mathrm{Zn}^{2+}(40)+$ citrate (50); $\rightarrow-$ BPMG (30) $+\mathbf{Z n}^{2+}(40)+$ citrate (100); $\triangle$ BPMG (30) $+\mathrm{Zn}^{2+}$ (40) + citrate (150); $\square$ BPMG (30) $+\mathbf{Z n}^{2+}$ (40) + citrate (200). 
slightly alkaline region, say $\mathrm{pH} 8.0$, the inhibition efficiency is slightly decreased except at a composition of 30 ppm each of BPMG and $\mathrm{Zn}^{2+}$ and $100 \mathrm{ppm}$ of citrate. At $\mathrm{pH} 9.0$, the ternary inhibitor system with the composition BPMG (30 ppm), $\mathrm{Zn}^{2+}(40 \mathrm{ppm})$ and citrate (150 ppm) shows an inhibition efficiency of $92 \%$ and the system with $30 \mathrm{ppm}$ each of BPMG and $\mathrm{Zn}^{2+}$ and $100 \mathrm{ppm}$ of citrate shows an inhibition efficiency of $80 \%$. From these results it may be concluded that the ternary system, BPMG- $\mathrm{Zn}^{2+}$-citrate, is effective in the $\mathrm{pH}$ range 5.0 to 9.0. The reasons for decrease in IE in more alkaline and more acidic environments are explained under mechanistic aspects.

\subsection{Potentiodynamic Polarization Studies}

The potentiodynamic polarization curves of carbon steel electrode in $200 \mathrm{ppm} \mathrm{NaCl}$ solution at $\mathrm{pH} 7$ in the absence and presence of various inhibitor combinations are shown in Figure 6. The Tafel parameters derived from these curves and the inhibition efficiency values $\left(\mathrm{IE}_{\mathrm{p}}\right)$ arelisted in Table 1. The corrosion potential $\left(\mathrm{E}_{\text {corr }}\right)$ in case of the control is $-323.4 \mathrm{mV}$ vs. SCE and the corresponding corrosion current density ( $\mathrm{i}_{\text {corr }}$ ) is $12.84 \mu \mathrm{A} / \mathrm{cm}^{2}$. The combination of BPMG (40 ppm) and $\mathrm{Zn}^{2+}$ (30 ppm) significantly decreased both the anodic and cathodic current density values when compared to the control. It is, thus, evident that this formulation acts as an effective mixed type inhibitor. There is a slight shift in corrosion potential to cathodic side and the shift in cathodic Tafel slope is greater than the shift in anodic Tafel slope. The corrosion current density is significantly decreased from 12.84 to $1.38 \mu \mathrm{A} / \mathrm{cm}^{2}$, corresponding to an inhibition efficiency of $89.25 \%$. Although similar results were obtained with the combination of BPMG (20 ppm) and $\mathrm{Zn}^{2+}$

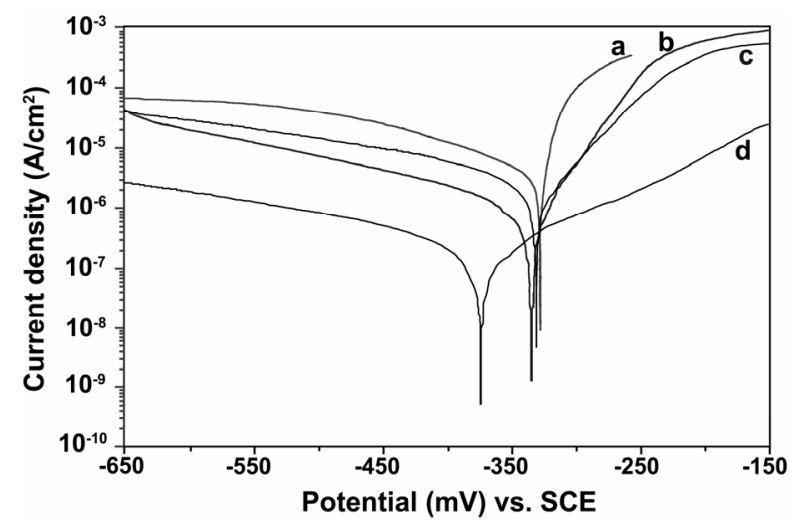

Figure 6. Potentiodynamic polarization curves for carbon steel in various aqueous environments: (a) $\mathrm{NaCl}(200 \mathrm{ppm})$; (b) $\mathrm{NaCl}\left(200\right.$ ppm) + BPMG (40 ppm) $+\mathrm{Zn}^{2+}$ (30 ppm); (c) $\mathrm{NaCl}$ (200 ppm) + BPMG (20 ppm) $+\mathrm{Zn}^{2+}$ (30 ppm); (d) $\mathrm{NaCl}(200 \mathrm{ppm})+\mathrm{BPMG}(20 \mathrm{ppm})+\mathrm{Zn}^{2+}(30 \mathrm{ppm})+$ citrate $(100 \mathrm{ppm})$.
Table 1. Tafel parameters for carbon steel in $200 \mathrm{ppm} \mathrm{NaCl}$ environment in the absence and presence of inhibitor formulations.

\begin{tabular}{|c|c|c|c|c|c|c|c|}
\hline \multicolumn{3}{|c|}{ Concentration (ppm) } & \multicolumn{4}{|c|}{ Tafel parameters } & \multirow{2}{*}{$\begin{array}{l}\mathrm{IE}_{\mathrm{p}} \\
(\%)\end{array}$} \\
\hline a & $\mathrm{b}$ & $\mathrm{c}$ & $\begin{array}{c}\mathrm{E}_{\text {corr }} \\
\text { (mV vs. SCE }\end{array}$ & $\begin{array}{c}\mathrm{i}_{\text {corr }} \\
\left(\mu \mathrm{A} / \mathrm{cm}^{2}\right)\end{array}$ & $\begin{array}{c}\beta_{\mathrm{a}} \\
(\mathrm{mV})\end{array}$ & $\begin{array}{c}\beta_{\mathrm{c}} \\
(\mathrm{mV})\end{array}$ & \\
\hline 0 & 0 & 0 & -323.4 & 12.84 & 45 & 132 & - \\
\hline 40 & 30 & 0 & -334.9 & 1.38 & 63 & 104 & 89.25 \\
\hline 20 & 30 & 0 & -330.8 & 7.11 & 54 & 112 & 44.62 \\
\hline 20 & 30 & 100 & -373.2 & 0.65 & 69 & 57 & 94.94 \\
\hline
\end{tabular}

a: $\mathrm{BPMG} ; \mathrm{b}: \mathrm{Zn}^{2+}$; c: Citrate.

(30 ppm), the $i_{\text {corr }}$ value is decreased from 12.84 to 7.11 $\mu \mathrm{A} / \mathrm{cm}^{2}$, corresponding to an inhibition efficiency of only $44.62 \%$. By the addition of $100 \mathrm{ppm}$ of citrate to the above formulation, the corrosion potential is shifted towards more cathodic side i.e., $-373.2 \mathrm{mV}$ vs. SCE and the corrosion current density is decreased from 12.84 to $0.65 \mu \mathrm{A} / \mathrm{cm}^{2}$. Such significant reduction in corrosion current density indicates the decrease in corrosion rate in presence of the ternary inhibitor system and exhibits an inhibition efficiency of $94.94 \%$. In case of the ternary formulation also, the shift in cathodic Tafel slope is higher than that in anodic Tafel slope. All these results indicate that the ternary inhibitor formulation retards both the anodic dissolution of carbon steel and oxygen reduction at cathodic sites in the corrosion inhibition process. Nevertheless, the effect on cathodic reaction is more pronounced. Similar phosphonate-based formulations were reported to be mixed inhibitors in the literature $[6,8,9,24]$. Thus, the results of potentiodynamic polarization studies infer the synergistic effect of citrate as well as the synergistic effect of the ternary inhibitor formulation in corrosion control of carbon steel.

\subsection{Electrochemical Impedance Studies}

Nyquist plots for carbon steel immersed in 200 ppm of $\mathrm{NaCl}$ solution at $\mathrm{pH} 7$ in the absence and presence of various formulations are shown in Figure 7. In case of the control as well as in presence of various formulations, the Nyquist plots are found to be depressed semicircles instead of ideal semicircles. This kind of phenomenon is called dispersing effect [25]. When the complex plane impedance contains a depressed semicircle with centre below the real axis, which is characteristic for solid electrodes, it is often attributed to roughness and inhomogeneities of the solid surface [26]. It is also attributed to the distribution of active sites, adsorption of inhibitor molecules and formation of porous layers [27].

In such cases, the parallel network charge transfer resistance-double layer capacitance $\left(\mathrm{R}_{\mathrm{ct}}-\mathrm{C}_{\mathrm{dl}}\right)$ is a poor 


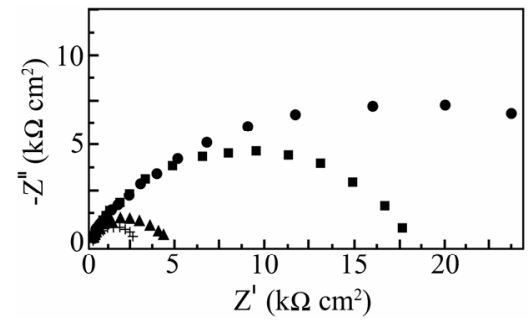

Figure 7. Nyquist plots for carbon steel in various aqueous environments, (+) $\mathrm{NaCl}(200 \mathrm{ppm})$; (a) $\mathrm{NaCl}(200 \mathrm{ppm})+$ BPMG (40 ppm) $+\mathrm{Zn}^{2+}(30 \mathrm{ppm}) ;(\Delta) \mathrm{NaCl}(200 \mathrm{ppm})+$ BPMG (20 ppm) $+\mathrm{Zn}^{2+}(30 \mathrm{ppm}) ;(\bullet) \mathrm{NaCl}(200 \mathrm{ppm})+$ BPMG (20 ppm) + $\mathrm{Zn}^{2+}(30 \mathrm{ppm})+$ citrate (100 ppm).

approximation especially for systems where an efficient inhibitor is present. Due to the fact that the double layer does not behave as an ideal capacitor in presence of the dispersing effect, a constant phase element (CPE) is substituted for the capacitor to fit the impedance behavior of the electrical double layer more accurately [28-31]. CPE can thus be regarded as a non-ideal capacitance [32]. The admittance and impedance of a CPE are, respectively defined as

$$
\begin{aligned}
& Y_{\mathrm{CPE}}=Y_{o}(j \omega)^{n} \\
& Z_{\mathrm{CPE}}=A(j \omega)^{-n}
\end{aligned}
$$

where $\omega$ is the angular frequency, $Y_{o}$ is the modulus which represents different quantities, depending on the value of CPE exponent, $\mathrm{n}$. A is the proportional factor, which is the reciprocal of modulus [29-31,33]. For a highly polished electrode, the value of $\mathrm{n}$ is close to 1.0. The lower the value of $n$, the rougher is the electrode surface. It can be seen that when $n=1$, the element CPE becomes an ideal capacitor. The value of $\mathrm{n}$ is also related to the inherent physical and chemical heterogeneous nature of the solid surface, the presence of a porous corrosion product layer and non-uniform distribution of current density on the surface [34-36].

All the Nyquist plots obtained in the present study are characterized by single time constant. The experimental data obtained from these plots are fitted by the equivalent electrical circuit shown in Figure 8. Such an equivalent circuit was also discussed by several researchers [30,31, 37], who obtained similar depressed semicircles with single time constant. The impedance parameters viz., charge transfer resistance $\left(\mathrm{R}_{\mathrm{ct}}\right)$, constant phase element (CPE) and CPE exponent (n) obtained from the Nyquist plots and the calculated inhibition efficiency values $\left(\mathrm{IE}_{\mathrm{i}}\right)$ are shown in Table 2. Charge transfer resistance $\left(\mathrm{R}_{\mathrm{ct}}\right)$ and the non-ideal capacitance (CPE) are the two important parameters related to corrosion processes at the metal/solution interface. The former one is directly related to the rate of corrosion reaction at the interface

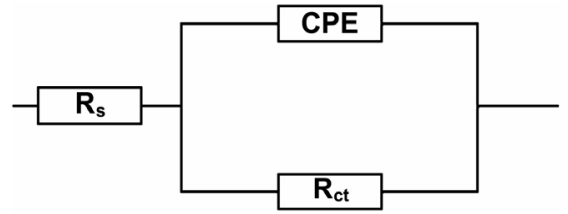

Figure 8. Equivalent electrical circuit used to fit the impedance data.

Table 2. Impedance parameters for carbon steel in 200 ppm $\mathrm{NaCl}$ environment in the absence and presence of inhibitor formulations.

\begin{tabular}{ccccccc}
\hline \multicolumn{6}{c}{ Concentration (ppm) } & \multicolumn{5}{c}{ Impedance parameters } & \multirow{2}{*}{$\mathrm{IE}_{\mathrm{i}}(\%)$} \\
\cline { 1 - 5 } $\mathrm{a}$ & $\mathrm{b}$ & $\mathrm{c}$ & $\begin{array}{c}\mathrm{R}_{\mathrm{ct}} \\
\left(\Omega \mathrm{cm}^{2}\right)\end{array}$ & $\begin{array}{c}\mathrm{CPE} \\
\left(\mu \mathrm{F} / \mathrm{cm}^{2}\right)\end{array}$ & $\mathrm{n}$ & \\
\hline 0 & 0 & 0 & 2575 & 13.41 & 0.592 & - \\
40 & 30 & 0 & 17469 & 7.52 & 0.863 & 85.26 \\
20 & 30 & 0 & 4420 & 8.91 & 0.697 & 41.74 \\
20 & 30 & 100 & 36002 & 3.83 & 0.879 & 92.84 \\
\hline
\end{tabular}

a: $\mathrm{BPMG} ; \mathrm{b}: \mathrm{Zn}^{2+}$; c: Citrate.

while the latter is related to the structure of electrical double layer at the interface. During corrosion inhibition by the adsorption of inhibitor molecules, high $\mathrm{R}_{\mathrm{ct}}$ values can be obtained due to slower corroding system $[38,39]$. Consequently, the decrease in CPE can result from the decrease of the local dielectric constant and/or from the increase of thickness of electrical double layer, which suggests an adsorption of the inhibitor molecules on the metal surface [40]. Hence, for an effective inhibition process, there will be an increase in $\mathrm{R}_{\mathrm{ct}}$ and decrease in CPE.

In the present study, in the presence of the control alone, a small semicircle with an $\mathrm{R}_{\text {ct }}$ value of $2575 \Omega$ is observed. When the combination of $40 \mathrm{ppm}$ of BPMG and $30 \mathrm{ppm}$ of $\mathrm{Zn}^{2+}$ is considered in the presence of control, a large depressed semicircle is observed from high frequency to low frequency regions in the Nyquist plot, indicating that the charge transfer resistance becomes dominant in the corrosion processes due to the presence of protective film on the metal surface. This result is supported by the significant decrease in CPE and an increase in $\mathrm{n}$ value. The semicircle obtained in presence of BPMG- $\mathrm{Zn}^{2+}$ represents the $\mathrm{R}_{\mathrm{ct}}$ value of $17469 \Omega$, which is about six times greater than that observed in case of the control. The CPE value at the metal/solution interface is found to decrease from $13.41 \mu \mathrm{F} / \mathrm{cm}^{2}$ in case of the control to $7.52 \mu \mathrm{F} / \mathrm{cm}^{2}$ in case of the binary inhibitor formulation. The value of $\mathrm{n}$ is increased to 0.863 in presence of the binary inhibitor system. When the combination of $20 \mathrm{ppm}$ of BPMG and $30 \mathrm{ppm}$ of $\mathrm{Zn}^{2+}$ is considered, the value of $\mathrm{R}_{\mathrm{ct}}$ obtained is $4420 \Omega$, correspond- 
ing to an inhibition efficiency of only $41.74 \%$. But when $100 \mathrm{ppm}$ of citrate is added to this formulation, a very high charge transfer resistance of $36,002 \Omega$ is obtained, which is more than twice the $R_{c t}$ value obtained in case of the effective binary combination of BPMG- $\mathrm{Zn}^{2+}$. The $\mathrm{CPE}$ value is found to decrease from $13.41 \mu \mathrm{F} / \mathrm{cm}^{2}$ in case of the control to $3.83 \mu \mathrm{F} / \mathrm{cm}^{2}$ in case of the ternary inhibitor formulation. This is because of the replacement of water molecules in the electrical double layer by the organic molecules having low dielectric constants [41]. The value of $\mathrm{n}$ is considerably increased to 0.879 in presence of the ternary inhibitor system suggesting the decrease of inhomogeneity of the interface during inhibition. All these results indicate that there is formation of a protective film in the presence of the ternary inhibitor formulation. Several authors, who studied the inhibitory effects of phosphonate-based corrosion inhibitors, also reported that there is formation of thick and less permeable protective film on the metal surface $[5,6,8]$. They also concluded that the protective film consists of phosphonate-metal complexes. The impedance results of the present study also infer the synergistic action operating between BPMG, $\mathrm{Zn}^{2+}$ and citrate ions. This inference is in agreement with the inferences drawn from gravimetric studies and potentiodynamic polarization studies. It may be noted that the inhibition efficiency values obtained from impedance studies are in agreement with those values obtained from polarization studies.

\subsection{X-Ray Photoelectron Spectroscopic Studies}

The XPS deconvolution spectra of the individual elements present in the surface films formed in control solution in the absence and presence of the inhibitor formulation are shown in Figures 9-14. The interpretation of all these spectra is done with the help of the data of the elemental binding energies reported in literature and also with the help of the reports published on the analysis of XPS spectra of the surface films.

The $\mathrm{Fe} 2 \mathrm{p}$ deconvolution spectrum in case of the control is shown in Figure 9(a). Two peaks are observed, one at $710.8 \mathrm{eV}$ corresponding to $\mathrm{Fe} 2 \mathrm{p}_{3 / 2}$ and the other one at $724.2 \mathrm{eV}$ corresponding to $\mathrm{Fe} 2 \mathrm{p}_{1 / 2}$ electron. The peak due to $\mathrm{Fe} 2 \mathrm{p}_{3 / 2}$ is interpreted for the determination of chemical state of iron in the surface film. The peak of $\mathrm{Fe} 2 \mathrm{p}_{3 / 2}$ at $710.8 \mathrm{eV}$ is the one, shifted from $707.0 \mathrm{eV}$, the characteristic elemental binding energy of $\mathrm{Fe} 2 \mathrm{p}_{3 / 2}$ electron [42]. Such a large shift of $3.8 \mathrm{eV}$ suggests that iron is present in $\mathrm{Fe}^{3+}$ state in the surface film. In the literature $[8,43]$, the peak at $711.0 \mathrm{eV}$ was ascribed to the presence of $\mathrm{FeOOH}$ and $\mathrm{Fe}(\mathrm{OH})_{3}$. The binding energy of $\mathrm{Fe} 2 \mathrm{p}_{3 / 2}$ due to $\gamma-\mathrm{Fe}_{2} \mathrm{O}_{3}$ was reported to be $711.0 \pm 0.15$ $\mathrm{eV}$ [44]. It was also reported that the mean binding energy of $\mathrm{Fe} 2 \mathrm{p}_{3 / 2}$ in $\alpha$-FeOOH is $711.0 \pm 0.2 \mathrm{eV}$ [44].
Maroie et al. reported that the binding energy value of $711.0 \mathrm{eV}$ for $\mathrm{Fe} 2 \mathrm{p}_{3 / 2}$ is due to ferric oxide species [45]. Thus, the presence of a peak due to $\mathrm{Fe} 2 \mathrm{p}_{3 / 2}$ observed in case of the control at $710.8 \mathrm{eV}$ can be ascribed due to the presence of iron in the form of $\gamma-\mathrm{Fe}_{2} \mathrm{O}_{3}, \mathrm{Fe}_{3} \mathrm{O}_{4}$ and $\mathrm{FeOOH}$. In the case of the inhibitor system, the XPS (Figure 9(b)) shows the $\mathrm{Fe} 2 \mathrm{p}_{3 / 2}$ peak at $710.0 \mathrm{eV}$ and the $\mathrm{Fe} 2 \mathrm{p}_{3 / 2}$ peak at $722.7 \mathrm{eV}$. Thus, the peak positions obtained in case of the inhibitor formulation infer the presence of oxides and hydroxides like $\mathrm{Fe}_{2} \mathrm{O}_{3}, \mathrm{Fe}_{3} \mathrm{O}_{4}$, $\mathrm{FeOOH}$ and also involvement of $\mathrm{Fe}^{3+}$ in the complex formation with the inhibitor molecules. No peak is observed due to elemental iron in the case of control and ternary inhibitor formulation. This result infers the formation of thick films in both the cases. The film is non-protective in the case of control and highly protective in the presence of inhibitor molecules. If the intensities of $\mathrm{Fe} 2 \mathrm{p}_{3 / 2}$ peaks are compared, they are $4600 \mathrm{cps}$ for control and only $400 \mathrm{cps}$ for the ternary inhibitor system. Such a large decrease in the intensity of $\mathrm{Fe} 2 \mathrm{p}$ peak in the presence of the inhibitor formulation can be understood because of formation of protective film and consequently less corrosion of iron and less amount of iron oxide. The binding energy of $\mathrm{Fe}^{2+}$ state in iron oxides is reported to be around $708.5 \mathrm{eV}$ [46]. The absence of any peak in this region in the present study also supports that iron does not exist in $\mathrm{Fe}^{2+}$ state.

The XPS spectrum of phosphorus is shown in Figure 10. Two $P 2 p$ peaks are observed one each at $132.4 \mathrm{eV}$

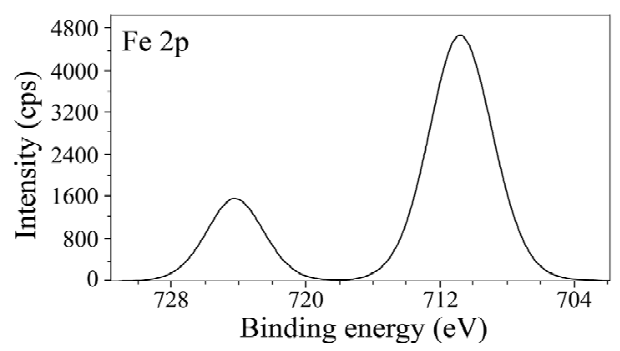

(a)

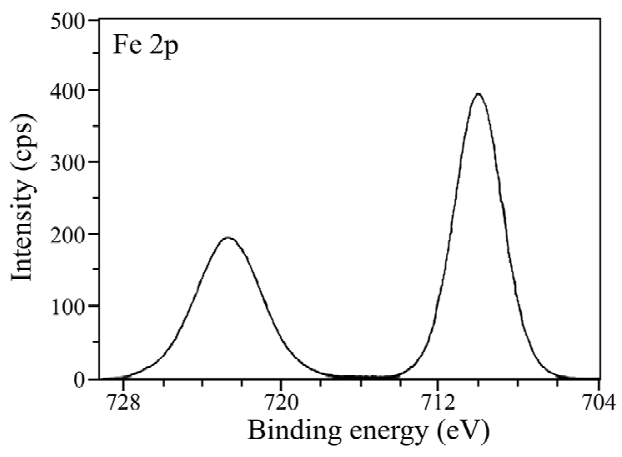

(b)

Figure 9. XPS deconvolution spectra of Fe 2p in the surface films (a) control; (b) inhibitor system. 


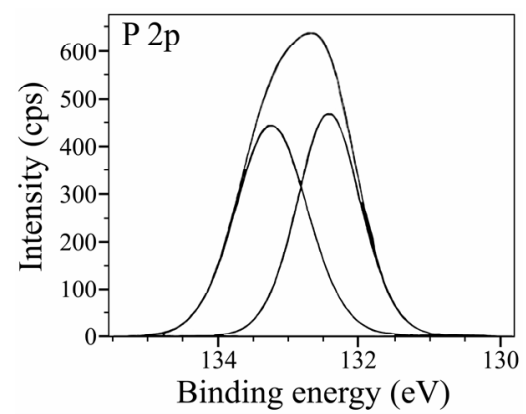

Figure 10. XPS deconvolution spectrum of $P$ 2p.

and $133.2 \mathrm{eV}$. In the literature [47], it was reported that the P $2 p$ peak could be observed in the range of 132.9 to $133.8 \mathrm{eV}$, for iron or steels immersed in the solutions containing phosphonates, orthophosphates and polyphosphates. Nakayama obtained a P $2 p$ peak at $133.0 \mathrm{eV}$ and attributed it to the presence of phosphonate compounds [48]. Felhosi et al. observed a P 2p peak at 132.1 $\mathrm{eV}$ in the XPS of the surface film formed on carbon steel when immersed in a solution containing $\mathrm{Zn}^{2+}$ and HEDP [5]. They interpreted this peak due to the presence of [Zn-HEDP] complex in the surface film. In the studies on the mixtures of salts of phosphonocarboxylic acids and fatty amines as inhibitors for corrosion of carbon steel, it was reported that the P $2 p$ peak was observed at 132.1 $\mathrm{eV}$ and was interpreted it due to the presence of phosphonate group in the surface film [49]. In the light of these reports, the P $2 p$ peaks observed in the present study suggest the presence of BPMG in the surface film formed in the case of the inhibitor. Figure 11 shows the XPS spectrum of N 1s with a single peak at $399.5 \mathrm{eV}$. This peak is shifted from $398.0 \mathrm{eV}$, the characteristic elemental binding energy of $\mathrm{N} 1 \mathrm{~s}$ electron [42]. The shift may be attributed to the presence of BPMG molecules in the surface film probably in the form of a complex with $\mathrm{Fe}(\mathrm{III})$ and $\mathrm{Zn}(\mathrm{II})$. It was reported in the literature [50] that $\mathrm{N} 1 \mathrm{~s}$ peak observed at $399.7 \mathrm{eV}$ could be assigned to the presence of $(=\mathrm{N}-)$ in the molecule adsorbed on the metal surface. Meneguzzi et al. reported that the peak at $399.9 \mathrm{eV}$ could be attributed to the neutral imine $(-\mathrm{N}=)$ and amine (-N-H) nitrogen atoms [51].

The XPS spectra of $\mathrm{C}$ 1s are shown in Figure 12. C 1s spectrum in case of the control shows a single peak at $284.6 \mathrm{eV}$. This peak is due to contamination from the vacuum system and chamber during the analysis [52]. In case of the inhibitor formulation, the $\mathrm{C} 1 \mathrm{~s}$ spectrum contains three peaks, one is the high intense peak at 284.4 $\mathrm{eV}$ and the other two are low intense peaks at $285.9 \mathrm{eV}$ and $288.2 \mathrm{eV}$. Ochoa et al. in their studies on the mixtures of salts of phosphonocarboxylic acids and fatty amines as inhibitors for corrosion of carbon steel reported the $\mathrm{C} 1 \mathrm{~s}$ peak at $284.5 \mathrm{eV}$ [49]. This signal was

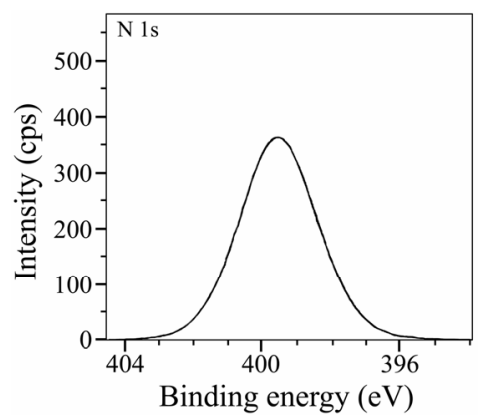

Figure 11. XPS deconvolution spectrum of $N$ s.

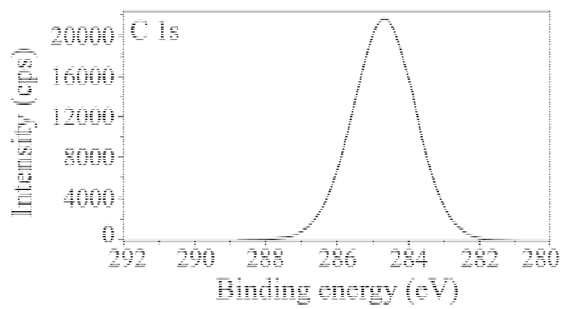

(a)

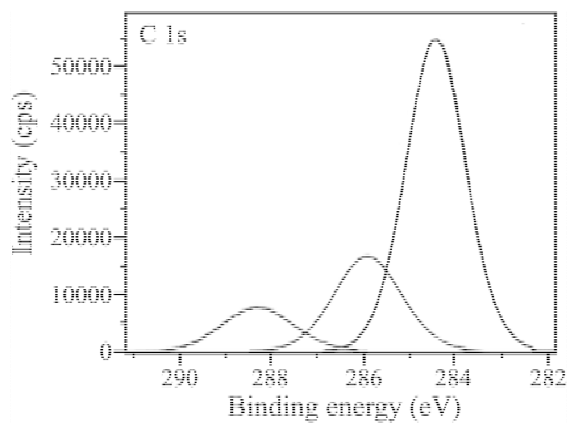

(b)

Figure 12. XPS deconvolution spectra of $C 1 s$ in the surface films (a) control; (b) inhibitor system.

accounted for by the presence of the inhibitor molecules on the steel surface. Gunasekaran and Chauhan studied the corrosion inhibition of mild steel by a plant extract and they obtained $\mathrm{C}$ 1s peaks at 285,287 and $288.6 \mathrm{eV}$ [31]. They interpreted these peaks due to C-C, C-O and $\mathrm{C}=\mathrm{O}$ bonds because of the organic molecules present in the plant extract. Aramaki and Shimura obtained a peak of organic carbon at $284.5 \mathrm{eV}$ and they inferred that it is due to adsorbed organic inhibitor molecules on the surface [53]. BPMG and citrate have various carbon environments and hence the three peaks observed in presence of the inhibitor formulation indicate the presence of inhibitor species in the surface film.

The XPS spectra of $\mathrm{O}$ 1s are presented in Figure 13. In case of the control (Figure 13(a)), two peaks corresponding to $\mathrm{O} 1 \mathrm{~s}$ are observed, one at $530.1 \mathrm{eV}$ and the other one at $533.0 \mathrm{eV}$. The latter peak is due to adsorbed water on the surface $[46,48,49,54]$. O 1 s peak observed at 


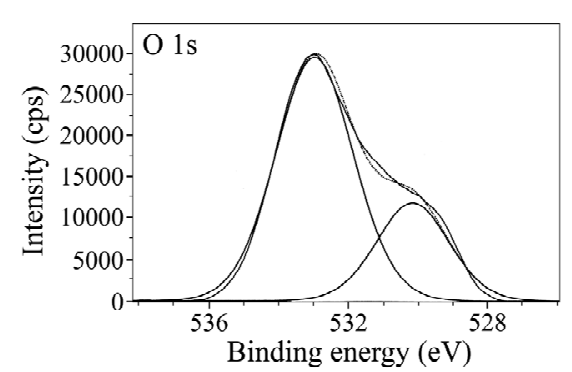

(a)

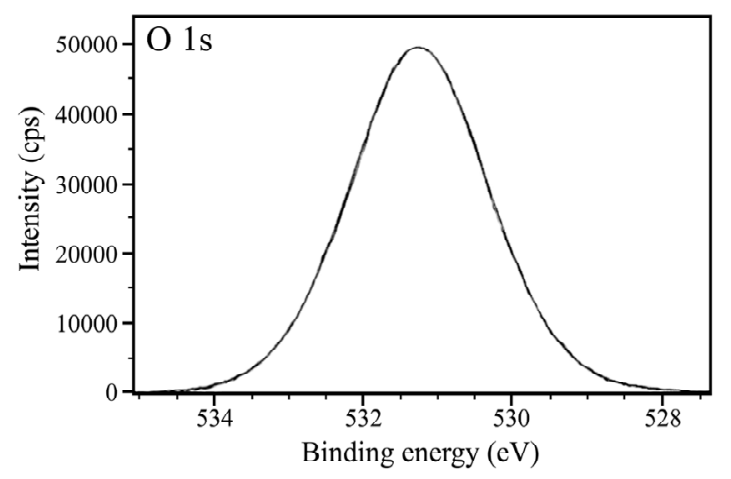

(b)

Figure 13. XPS deconvolution spectra of $O 1 \mathrm{~s}$ in the surface films (a) control; (b) inhibitor system.

$530.1 \mathrm{eV}$ is due to $\mathrm{O}^{2}$. Pech-Canul and Bartolo-Perez obtained O 1s peak at approximately $529.8 \mathrm{eV}$ and attributed it to $\mathrm{O}^{2-}$ [8]. Karman et al. studied the role of oxide layer formation during corrosion inhibition of mild steel in neutral aqueous media [54]. They assigned the $\mathrm{O}$ $1 \mathrm{~s}$ peak at $\sim 530 \mathrm{eV}$ to $\mathrm{O}^{2-}$. In the present study, the presence of $\mathrm{O}^{2-}$ in the surface film formed in the presence of control may be in the form of oxides/hydroxides of $\mathrm{Fe}(\mathrm{III})$. In case of the inhibitor formulation, a single $\mathrm{O}$ $1 \mathrm{~s}$ peak of high intensity positioned at $531.5 \mathrm{eV}$ is observed. Fang et al. ascribed the $\mathrm{O} 1 \mathrm{~s}$ peak observed at $531.3 \mathrm{eV}$ to the complex formed between iron and phosphonate [55]. Pech-Canul and Bartolo-Perez observed the $\mathrm{O} 1 \mathrm{~s}$ peak at $531.3 \mathrm{eV}$, which was ascribed to $\mathrm{OH}^{-}$from hydrous iron oxides and to the complex formed between iron and phosphonate group [8]. It was also mentioned in their paper that such hydrous ferric oxides consist of $\mathrm{Fe}(\mathrm{OH})_{3}$ and $\mathrm{FeOOH}$. Felhosi et al. studied the effects of bivalent cations on corrosion inhibition of steel by HEDP [5]. They mentioned that the $\mathrm{O} 1 \mathrm{~s}$ peak at $531.4 \mathrm{eV}$ is due to $\mathrm{Fe}-\mathrm{OH}$ bond. Asami et al. observed $\mathrm{O} 1 \mathrm{~s}$ peak at $531.5 \mathrm{eV}$ in their study and attributed it to oxygen with a kind of Fe-O-H bond [46]. In the light of these results and interpretations reported in literature, the $\mathrm{O} 1 \mathrm{~s}$ peaks of high intensity observed in the present study may be interpreted as follows. The XPS of surface films show that besides oxygen, there is presence of carbon, nitrogen, phosphorus, iron and zinc in the surface film. That means
BPMG is present on the surface, zinc is present as $\mathrm{Zn}^{2+}$ and the interpretation given above in case of $\mathrm{Fe} 2 \mathrm{p}$ indicates the presence of $\mathrm{Fe}_{2} \mathrm{O}_{3}, \mathrm{Fe}_{3} \mathrm{O}_{4}$ and $\mathrm{FeOOH}$. Hence, $\mathrm{O} 1 \mathrm{~s}$ peaks can be ascribed to the presence of $\mathrm{Zn}(\mathrm{OH})_{2}$, $\mathrm{Fe}_{2} \mathrm{O}_{3}, \mathrm{Fe}_{3} \mathrm{O}_{4}, \mathrm{FeOOH}$ and oxygen of BPMG as well as citrate in the surface film. The disappearance of peak around $533.0 \mathrm{eV}$ in case of the inhibitor formulation indicates the absence of water molecules in the surface film as they have been completely replaced by the inhibitor molecules. A comparison of intensities of $\mathrm{O} 1 \mathrm{~s}$ peak in the control and in the presence of ternary inhibitor system is of interest. In comparison to the intensity of 29,500 cps in control, the intensity of $\mathrm{O} 1 \mathrm{~s}$ peak increases to around $50000 \mathrm{cps}$ in the presence of the inhibitor system. This increase is to be considered along with the high intensity of zinc (Figure 14), of carbon (Figure 12(b)) and of phosphorus (Figure 10). The intensity of O 1s peak is related mainly to oxygen in two phosphonate and one carboxylate groups of BPMG, oxygen of citrate ion, $-\mathrm{OH}$ group of $\mathrm{Zn}(\mathrm{OH})_{2}$ and to small amounts of oxides/hydroxides of iron.

Figure 14 presents the XPS deconvolution spectrum of zinc. The $\mathrm{Zn} 2 \mathrm{p}_{3 / 2}$ peak is observed at $1022.0 \mathrm{eV}$ and the $\mathrm{Zn} 2 \mathrm{p}_{1 / 2}$ peak at $1045.2 \mathrm{eV}$. $\mathrm{Zn} 2 \mathrm{p}_{3 / 2}$ peak is normally interpreted. The high intensity of the $Z n 2 p_{3 / 2}$ peak may be ascribed to the presence of $\mathrm{Zn}(\mathrm{OH})_{2}$ in the surface film and also to the involvement of $\mathrm{Zn}^{2+}$ in the complex formation with the inhibitor molecules. It was reported in literature that the $\mathrm{Zn} 2 \mathrm{p}_{3 / 2}$ peak at $1022.8 \mathrm{eV}$ was due to the presence of $\mathrm{Zn}(\mathrm{OH})_{2}$ in the surface film [56]. Felhosi et al. interpreted from the XPS analysis that there is formation of [Zn-HEDP] complex on the mild steel surface when immersed in a solution consisting of a mixture of HEDP and $\mathrm{Zn}^{2+}$ [5]. Along with the elements discussed above, the survey spectrum (not included in the paper) in case of the control has a low intensity chlorine peak at $200.0 \mathrm{eV}$. This is because some chloride ions reach the metal surface and are responsible for corrosion of the metal. The chlorine peak is not observed in the survey spectrum of the inhibited surface film, which indicates

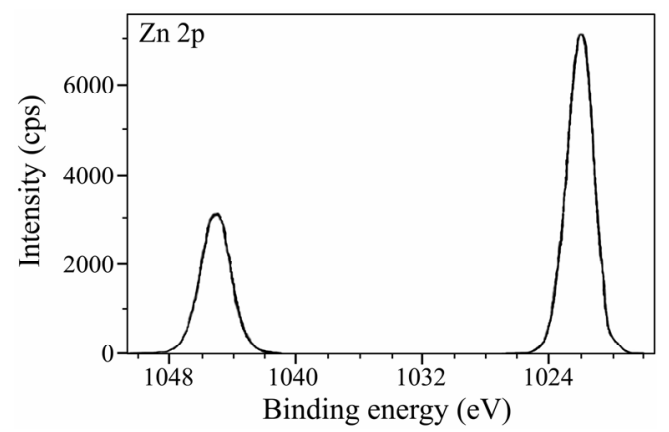

Figure 14. XPS deconvolution spectrum of $\mathrm{Zn} 2 \mathrm{p}$ in the surface film. 
that the protective film does not allow the aggressive ions to reach the metal surface. After consolidating all the inferences drawn from the XPS of individual elements present in surface film, it is suggested that the surface film in case of the inhibitor system consists of mainly [Zn(II)-BPMG-citrate] complex, $\mathrm{Zn}(\mathrm{OH})_{2}$ and small amounts of oxides/hydroxides of $\mathrm{Fe}(\mathrm{III})$. The complex may be chemisorbed on the metal surface and get attached to the $\mathrm{Fe}(\mathrm{III})$ ions.

\subsection{Interpretation of FTIR Spectra}

The reflection absorption FTIR spectra of the surface films formed on carbon steel in the absence and presence of the inhibitor formulation are shown in Figure 15. These spectra are interpreted by comparing with the FTIR spectra of pure BPMG and pure trisodium citrate (not shown here) as well as with the help of literature reports. In the FTIR spectrum of BPMG, multiple bands in the region, $900-1200 \mathrm{~cm}^{-1}$ were assigned to phosphonate group stretching frequencies. The peak at 1181 $\mathrm{cm}^{-1}$ can be assigned to $-\mathrm{PO}_{3}$ antisymmetric $\left(v_{\mathrm{as}}\right)$ stretching while the peak at $1080 \mathrm{~cm}^{-1}$ is assigned to symmetric $\left(v_{\mathrm{s}}\right)$ stretching of $-\mathrm{PO}_{3}$. The peak observed at $933.5 \mathrm{~cm}^{-1}$ can be attributed to the $\mathrm{P}-\mathrm{OH}$ stretching vibrations. In case of the inhibitor system, the $-\mathrm{PO}_{3}$ stretching is observed near $1110 \mathrm{~cm}^{-1}$. The P-OH stretching located at $915.3 \mathrm{~cm}^{-1}$ is observed to be weak. These results can be interpreted in terms of interaction between $\mathrm{P}_{-} \mathrm{O}^{-}$present in the phosphonate with metallic species, viz. $\mathrm{Zn}(\mathrm{II})$ and $\mathrm{Fe}(\mathrm{III})$ to form P-O-Zn and P-O-Fe bonds. This interpretation was also given by several authors, who worked on corrosion inhibition of carbon steel by phosphonates $[6,57,58]$. Carter et al. found that FTIR spectra obtained with an organic phosphonate on a steel substrate are consistent with the phosphonate reaction on steel to produce a metal salt [59]. It also suggests that phosphonates are coordinated with metal ions resulting in the formation of [metal-phosphonate] complexes on the metal surface. A weak band observed around $1325 \mathrm{~cm}^{-1}$ indicates the

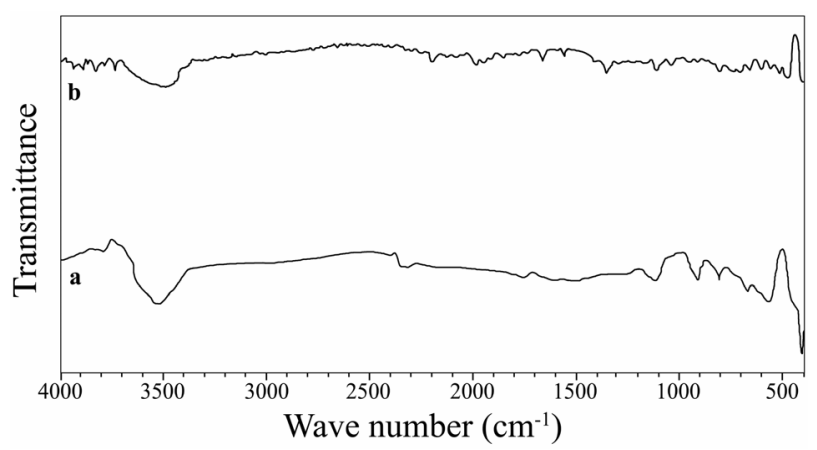

Figure 15. Reflection absorption FTIR spectra of the surface films (a) control; (b) ternary inhibitor system. presence of zinc hydroxide in the surface film $[58,60,61]$. An intense band at $1732 \mathrm{~cm}^{-1}$ in the FTIR spectrum of BPMG is the characteristic of uncoordinated, protonated carboxylate carbonyl group in BPMG. In the FTIR spectrum of pure trisodium citrate, the $\mathrm{C}=\mathrm{O}$ stretching frequency is observed at $1591.0 \mathrm{~cm}^{-1}$. Small peaks at 1690 $\mathrm{cm}^{-1}$ and $1560 \mathrm{~cm}^{-1}$ in the reflection absorption FTIR spectrum of the surface film indicate the presence of both BPMG and citrate ions in the surface film. The shifts in the stretching frequency are resulted due to the involvement of these ions in the complex formation. A band at $1050 \mathrm{~cm}^{-1}$ in case of the inhibitor system is due to C-N stretching vibration shifted from $1157 \mathrm{~cm}^{-1}$ observed in case of pure BPMG. The shift towards lower wave number indicates the formation of a coordinate bond between metal ions and phosphonate molecule. There are several bands in the region, $1200-400 \mathrm{~cm}^{-1}$, in both the spectra of surface films. Many of these peaks imply the presence of various oxides and hydroxides of iron like $\mathrm{Fe}_{3} \mathrm{O}_{4}$, $\mathrm{FeOOH}$ and $\mathrm{Fe}_{2} \mathrm{O}_{3}$ [48,53]. Shi Yee and Gan Moog Chow obtained peaks at $570 \mathrm{~cm}^{-1}$ and $630 \mathrm{~cm}^{-1}$ and assigned them to amorphous oxides of $\mathrm{Fe}_{2} \mathrm{O}_{3}$ and $\mathrm{Fe}_{3} \mathrm{O}_{4}$ [62]. Amar et al. obtained absorption peaks between 750 $1100 \mathrm{~cm}^{-1}$, in the spectra of metal surfaces in presence of $3 \% \mathrm{NaCl}$ solution [58]. They interpreted them to corrosion products of ferric hydroxide $(\gamma-\mathrm{FeOOH})$ and magnetite $\left(\mathrm{Fe}_{3} \mathrm{O}_{4}\right)$. A moderately intense and a broad band formed at $3540.8 \mathrm{~cm}^{-1}$, in case of the control, can be assigned to the presence of -OH group on the surface. This hydroxyl group may be in the form of $\mathrm{FeOOH}$ and/or $\mathrm{Fe}(\mathrm{OH})_{3}$ [63]. Such peaks are observed in the spectra of the inhibited surface film also. These peaks can be assigned to the - $\mathrm{OH}$ groups present in the inhibitor molecules, to $\mathrm{Zn}(\mathrm{OH})_{2}$ and a small contribution of hydroxide of Fe(III) present in the inhibited film. Thus, the reflection absorption FTIR spectrum of the surface film formed in presence of the ternary inhibitor formulation infers the presence of [ $\mathrm{Zn}(\mathrm{II})-\mathrm{BPMG}$-citrate] complex, $\mathrm{Zn}(\mathrm{OH})_{2}$ and small amounts of oxides and hydroxides of Fe(III).

The XPS spectrum and the reflection absorption FTIR spectrum of the surface film infers the presence of $\mathrm{Fe}(\mathrm{III})$, $\mathrm{Zn}(\mathrm{II}), \mathrm{BPMG}$ and citrate in the surface film. The shifts in binding energies of various elements and shifts in the absorption band frequencies of various functional groups inferred that BPMG and citrate are involved in the complex formation with $\mathrm{Zn}^{2+}$ and $\mathrm{Fe}^{3+}$. This inference is further supported by several studies reported in literature [6,64-66]. Based on all these literature reports on various phosphonates and the requirement of optimum concentration of zinc ions for effective inhibition and also on the high intensity $\mathrm{Zn} 2 \mathrm{p}$ peaks obtained from XPS spectrum, it can be inferred that $\mathrm{Zn}(\mathrm{II})$ and $\mathrm{Fe}(\mathrm{III})$ are involved in the complex formation with BPMG and citrate 
to form [Fe(III), Zn(II)-BPMG-citrate] polynuclear multiligand complex, which plays significant role in making the surface film protective.

\subsection{Surface Analysis by SEM}

Figure 16 shows the high resolution SEM images of the surfaces of carbon steel immersed for 7 days in the control in the absence and presence of the inhibitor, BPMG $(20 \mathrm{ppm})+\mathrm{Zn}^{2+}(30 \mathrm{ppm})+$ citrate $(100 \mathrm{ppm})$. Figure 16(a) reveals that the surface is severely corroded and there is formation of different forms of corrosion products (iron oxides) on the surface in the absence of the inhibitor. The entire surface is covered by a scale-like black corrosion product, on which there is growth of another corrosion product appearing in the form of white clusters at several sites. A very few of such clusters are shown at sub-micron level in Figure 16(b). The morphological features of the inhibited surface are shown in Figures 16(c) and (d). The corrosion product deposits observed in case of the control are not present on the inhibited surface. It indicates that the penetration of $\mathrm{Cl}^{-}$ ions of the environment on to the substrate is controlled effectively through good surface coverage by the inhibittor film. The higher magnification $(\times 5000)$ SEM image (Figure 16(d)) of the inhibited surface contains some low depth inhomogeneities on the surface. But the closer look at such sites reveals that the inhomogeneities are due to the structural defects of the metal substrate and that these sites are also covered by the inhibitor film. Thus, the inhibitor film covers the entire metal surface.
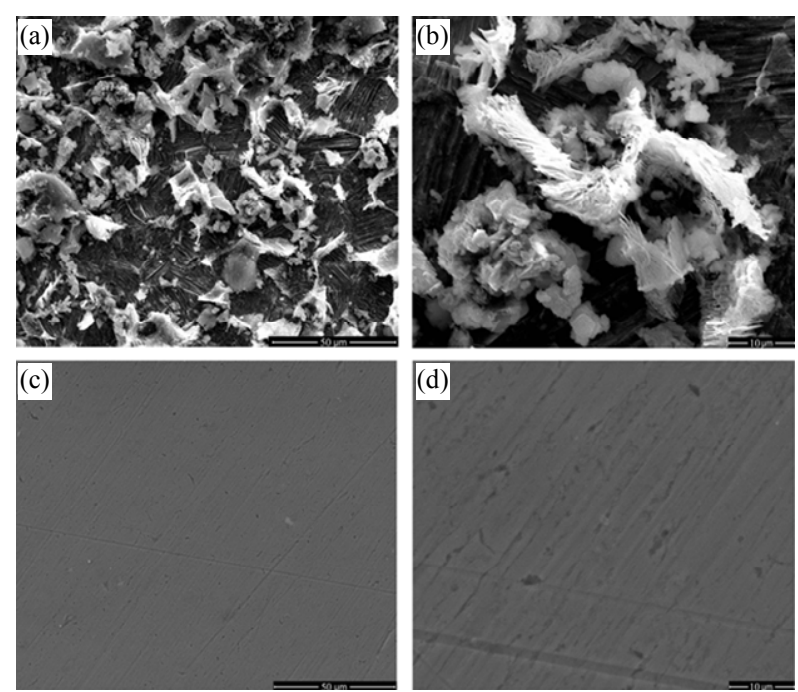

Figure 16. High-resolution SEM images of carbon steel surfaces after immersion in control in the absence and presence of the ternary inhibitor, BPMG (20 ppm) $+\mathrm{Zn}^{2+}$ (30 ppm) + citrate (100 ppm): (a) and (b) Control, (c) and (d) Inhibitor. (a) and (c) magnification $\times 1000$, (b) and (d) magnification $\times \mathbf{5 0 0 0}$.
This observation also accounts for the high inhibition efficiency values obtained during the gravimetric studies of the inhibitor system. From the SEM analysis it can be inferred that the surface film formed by the ternary inhibitor system exhibits good protective properties for carbon steel in low chloride media.

\subsection{Mechanism of Corrosion Inhibition}

In order to explain all the experimental results, a plausible mechanism of corrosion inhibition is proposed as follows:

1) The mechanism of corrosion of carbon steel in nearly neutral aqueous media is well established. The well-known reactions are mentioned below.

$$
\mathrm{Fe} \longrightarrow \mathrm{Fe}^{2+}+2 \mathrm{e}^{-}
$$

$\mathrm{Fe}^{2+}$ further undergoes oxidation in the presence of oxygen available in the aqueous solution $\left[\mathrm{O}_{2}\right]$.

$$
\mathrm{Fe}^{2+} \stackrel{\left[\mathrm{O}_{2}\right]}{\longrightarrow} \mathrm{Fe}^{3+}+\mathrm{e}^{-}
$$

The corresponding reduction reaction at cathodic sites in neutral and alkaline media is

$$
\mathrm{O}_{2}+2 \mathrm{H}_{2} \mathrm{O}+4 \mathrm{e}^{-} \longrightarrow 4 \mathrm{OH}^{-}
$$

$\mathrm{Fe}^{3+}$ ions produced at anodic areas and $\mathrm{OH}^{-}$ions produced at cathodic areas combine to form $\mathrm{Fe}(\mathrm{OH})_{3}$, $\left(\mathrm{Fe}_{2} \mathrm{O}_{3} \cdot \mathrm{H}_{2} \mathrm{O}\right)$ which gets precipitated on the surface of the metal due to its very low solubility product.

2) When BPMG, $\mathrm{Zn}^{2+}$ ions and citrate ions are added to the aqueous solution, both BPMG and citrate react with $\mathrm{Zn}^{2+}$ to form a ternary complex, $\left[\mathrm{Zn}^{2+}\right.$-BPMG-citrate]. It diffuses to the metal surface and binds to $\mathrm{Fe}(\mathrm{III})$ ions present on the surface. The cross-linkage and reorganization of such complex ions on the surface will produce a polymeric network structure. The resulting polynuclear complex, [Fe(III), Zn(II)-BPMG-citrate] covers the anodic sites and controls the corresponding anodic reaction.

$$
\begin{aligned}
& {[\mathrm{Zn}(\mathrm{II})-\mathrm{BPMG}-\mathrm{citrate}]+\mathrm{Fe}^{3+} \longrightarrow} \\
& {[\mathrm{Fe}(\mathrm{III}), \mathrm{Zn}(\mathrm{II})-\mathrm{BPMG} \text {-citrate }]}
\end{aligned}
$$

3) Free $\mathrm{Zn}^{2+}$ ions are available in the bulk of the solution because of relatively higher molar concentration of $\mathrm{Zn}^{2+}$ in the inhibitor mixture. These $\mathrm{Zn}^{2+}$ ions diffuse to the metal surface and react with $\mathrm{OH}^{-}$ions produced at the cathodic sites to form a precipitate of $\mathrm{Zn}(\mathrm{OH})_{2}$.

$$
\mathrm{Zn}^{2+}+2 \mathrm{OH}^{-} \longrightarrow \mathrm{Zn}(\mathrm{OH})_{2}
$$

The precipitate of $\mathrm{Zn}(\mathrm{OH})_{2}$ gets deposited on the cathodic sites and controls the cathodic partial reaction of corrosion process.

4) The inhibitor formulation is effective in the $\mathrm{pH}$ 
range, 5 - 9. At $\mathrm{pH} 10$ and above, higher concentration of $\mathrm{OH}^{-}$ions are available both in the bulk of the solution and on the surface. In such an environment, there is greater interference of $\mathrm{OH}^{-}$ions in the complexation [67] leading to the formation of [ $\mathrm{Zn}(\mathrm{II})-\mathrm{BPMG}$-citrate-OH] complex, which may not contribute to the formation of protective film on the metal surface. In acidic medium at $\mathrm{pH} \leq 4$, the ligand will be in the protonated form and do not coordinate with $\mathrm{Zn}(\mathrm{II})$ as effectively as the deprotonated ligands. Secondly, enough amount of $\mathrm{Zn}(\mathrm{OH})_{2}$ will not be formed on the cathodic sites. Hence, the inhibitor is not effective at $\mathrm{pH} \leq 4$.

5) Thus, BPMG, $\mathrm{Zn}^{2+}$ and citrate play very important role in the synergistic effect in controlling corrosion through the formation of protective film on the metal surface. It is inferred that the film may consist of various oxides/hydroxides like $\mathrm{Fe}_{2} \mathrm{O}_{3}, \mathrm{Fe}_{3} \mathrm{O}_{4} \cdot \mathrm{H}_{2} \mathrm{O}, \mathrm{FeOOH}$, $\mathrm{Zn}(\mathrm{OH})_{2}$ and a polynuclear multiligand complex, [Fe(III), $\mathrm{Zn}$ (II)-BPMG-citrate]. Each of these constituents contributes itself to make the film highly protective.

\section{Conclusions}

1) The ternary inhibitor system, BPMG- $\mathrm{Zn}^{2+}$-citrate, exhibits excellent synergism in the corrosion control of carbon steel in nearly neutral aqueous environment. The synergistic effect of citrate is established through the present study.

2) Optimum concentration of each of the components of the ternary inhibitor system is required for an effective inhibition.

3) The ternary inhibitor system is effective in the $\mathrm{pH}$ range $5-9$, which is generally applicable for cooling water systems.

4) The ternary inhibitor formulation acts as mixed type inhibitor controlling both the anodic and cathodic reactions.

5) Electrochemical impedance studies indicated the significant modification of the metal/solution interface by the formation of a dense and protective film in presence of the ternary inhibitor formulation.

6) The protective film consists of mainly [ $\mathrm{Zn}(\mathrm{II})$ BPMG-citrate] complex, $\mathrm{Zn}(\mathrm{OH})_{2}$ and small amounts of oxides/hydroxides of $\mathrm{Fe}(\mathrm{III})$. Presence of optimum amounts of all these compounds is required at a given $\mathrm{pH}$ value to make the surface film protective.

\section{REFERENCES}

[1] D.-J. Choi, S.-J. You and J.-G. Kim, "Development of an Environmentally Safe Corrosion, Scale, and Microorganism Inhibitor for Open Recirculating Cooling Systems," Materials Science and Engineering: A, Vol. 335, No.1-2, 2002, pp. 228-235.

doi.org/10.1016/S0921-5093(01)01928-1
[2] H. Amar, J. Benzakour, A. Derja, D. Villemin and B. Moreau, "A Corrosion Inhibition Study of Iron by Phosphonic Acids in Sodium Chloride Solution," Journal of Electroanalytical Chemistry, Vol. 558, 2003, pp. 131-139. doi.org/10.1016/S0022-0728(03)00388-7

[3] H. S. Awad and S. Turgoose, "Influence of Hardness Salts on Effectiveness of Zinc-1-Hydroxyethylidene-1,1Diphosphonic Acid (HEDP) Mixtures in Inhibiting the Corrosion of Mild Steel in Neutral Oxygen-Containing Solutions," Corrosion, Vol. 60, No. 12, 2004, pp. 11681179. doi.org/10.5006/1.3299230

[4] K. D. Demadis, S. D. Katarachia and M. Koutmos, "Crystal Growth and Characterization of Zinc-(Amino-Tris(Methylenephosphonate)) Organic-Inorganic Hybrid Networks and Their Inhibiting Effect on Metallic Corrosion," Inorganic Chemistry Communications, Vol. 8 No. 3, 2005, pp. 254-258. doi.org/10.1016/j.inoche.2004.12.019

[5] I. Felhosi, Zs. Keresztes, F. H. Karman, M. Mohai, I. Bertoti and E. Kalman, "Effects of Bivalent Cations on Corrosion Inhibition of Steel by 1-Hydroxyethane-1,1Diphosphonic Acid," Journal of The Electrochemical Society, Vol. 146, No. 3, 1999, pp. 961-969. doi.org/10.1149/1.1391706

[6] Y. Gonzalez, M. C. Lafont, N. Pebere and F. Moran, “A Synergistic Effect between Zinc Salt and Phosphonic Acid for Corrosion Inhibition of a Carbon Steel," Journal of Applied Electrochemistry, Vol. 26, No. 12, 1996, pp. 1259-1265. doi.org/10.1007/BF00249928

[7] M. A. Pech-Canul and L. P. Chi-Canul, "Investigation of the Inhibitive Effect of N-Phosphono-Methyl-Glycine on the Corrosion of Carbon Steel in Neutral Solutions by Electrochemical Techniques," Corrosion, Vol. 55, No. 10, 1999, pp. 948-956. doi.org/10.5006/1.3283931

[8] M. A. Pech-Canul and P. Bartolo-Perez, "Inhibition Effects of N-Phosphono-Methyl-Glycine/ $/ \mathrm{Zn}^{2+}$ Mixtures on Corrosion of Steel in Neutral Chloride Solutions," Surface and Coatings Technology, Vol. 184, No. 2-3, 2004, pp. 133-140. doi.org/10.1016/j.surfcoat.2003.11.018

[9] S. Rajendran, B. V. Appa Rao and N. Palaniswamy, "Synergistic Effect of 1-Hydroxyethane-1,1-Diphosphonic Acid and $\mathrm{Zn}^{2+}$ on the Inhibition of Corrosion of Mild Steel in Neutral Aqueous Environment," Anti-Corrosion Methods and Materials, Vol. 46, No. 1, 1999, pp. 23-28.

[10] L. Y. Reznik, L. Sathler, M. J. B. Cardoso and M. G. Albuquerque, "Experimental and Theoretical Structural Analysis of $\mathrm{Zn}$ (II)-1-Hydroxyethane-1,1-Diphosphonic Acid Corrosion Inhibitor Films in Chloride Ions Solution," Materials and Corrosion, Vol. 59, No. 8, 2008, pp. 685690. doi.org/10.1002/maco.200804108

[11] A. Shaban, E. Kalman and I. Biczo, "Inhibition Mechanism of Carbon Steel in Neutral Solution by N-PhosphonoMethyl-Glycine," Corrosion Science, Vol. 35, No. 5-8, 1993, pp. 1463-1470. doi.org/10.1016/0010-938X(93)90372-N

[12] J. Telegdi, M. M. Shaglouf, A. Shaban, F. H. Karman, I. Betroti, M. Mohai and E. Kalman, "Influence of Cations on the Corrosion Inhibition Efficiency of Aminophosphonic Acid," Electrochimica Acta, Vol. 46, No. 24-25, 2001, pp. 3791-3799. 
doi.org/10.1016/S0013-4686(01)00666-1

[13] H. S. Awad, "The Effect of Zinc-to-HEDP Molar Ratio on the Effectiveness of Zinc-1-Hydroxyethylidene-1,1Diphosphonic Acid in Inhibiting Corrosion of Carbon Steel in Neutral Solutions," Anti-Corrosion Methods and Materials, Vol. 52, No. 1, 2005, pp. 22-28.

[14] J. Jaworska, H. V. Genderen-Takken, A. Hanstveit, E. Plassche and T. Feijtel, "Environmental Risk Assessment of Phosphonates, Used in Domestic Laundry and Cleaning Agents in the Netherlands," Chemosphere, Vol. 47, No. 6, 2002, pp. 655-665. doi.org/10.1016/S0045-6535(01)00328-9

[15] B. V. Appa Rao, M. Venkateswara Rao, S. Srinivasa Rao and B. Sreedhar, "Synergistic Effect of N,N-Bis(Phosphonomethyl) Glycine and Zinc Ions in Corrosion Control of Carbon Steel in Cooling Water Systems," Chemical Engineering Communications, Vol. 198, 2011, pp. 1505-1529. doi.org/10.1080/00986445.2010.525200

[16] S. Westerback, K. S. Rajan and A. E. Martell, "New Multidentate Ligands. III. Amino Acids Containing Methylenephosphonate Groups," Journal of American Chemical Society, Vol. 87, No. 12, 1965, pp. 2567-2572. doi.org/10.1021/ja01090a008

[17] P. Amico, P. G. Daniele, V. Cucinotta, E. Rizzarelli and S. Sammartano, "Equilibrium Study Of Iron(II) and Manganese(II) Complexes with Citrate Ion in Aqueous Solution: Relevance to Coordination of Citrate to the Active site of Aconitase and to Gastrointestinal Absorption of Some Essential Metal Ions," Inorganica Chimica Acta, Vol. 36, 1979, pp. 1-7. doi.org/10.1016/S0020-1693(00)89363-9

[18] S. R. Hurford, C. R. Morris, J. A. Vesey, D. R. Williams, D. Cummins, P. I. Riley, G. L. Christie and J. R. Duffield, "Thermodynamic Formation Constants and Solid State Properties for the Interaction of $\mathrm{Zn}$ (II) Ions with Citrate, Phenolsulphonate, Monofluorophosphate, and Saccharinate," Journal of Inorganic Biochemistry, Vol. 42, No. 4, 1991, pp. 273-287.

doi.org/10.1016/0162-0134(91)84042-8

[19] L-C Konigsberger, E. Konigsberger, P. M. May and G. T. Hefter, "Complexation of Iron(III) and Iron(II) by Citrate. Implications for Iron Speciation in Blood Plasma," Journal of Inorganic Biochemistry, Vol. 78, No. 3, 2000, pp. 175-184. doi.org/10.1016/S0162-0134(99)00222-6

[20] ASTM Standard G31-72(1999), "Standard Practice for Laboratory Immersion Corrosion Testing of Metals," ASTM International, West Conshohocken, 2004.

[21] R. A. Freeman and D. C. Silverman, "Error Propagation in Coupon Immersion Tests," Corrosion, Vol. 48, No. 6, 1992, pp. 463-466. doi.org/10.5006/1.3315961

[22] M. Elachouri, M. S. Hajji, M. Salem, S. Kertit, J. Aride, R. Coudert and E. Essassi, "Some Nonionic Surfactants as Inhibitors of the Corrosion of Iron in Acid Chloride Solutions," Corrosion, Vol. 52, No. 2, 1996, pp. 103-108. doi.org/10.5006/1.3292100

[23] S. Rajendran, S. M. Reenkala, N. Anthony and R. Ramaraj, "Synergistic Corrosion Inhibition by the Sodium Dodecylsulphate- $\mathrm{Zn}^{2+}$ System," Corrosion Science,
Vol. 44, No. 10, 2002, pp. 2243-2252.

doi.org/10.1016/S0010-938X(02)00052-5

[24] B. V. Appa Rao, S. Srinivasa Rao and M. Venkateswara Rao, "Environmentally Friendly Ternary Inhibitor Formulation Based on N,N-Bis(Phosphonomethyl) Glycine," Corrosion Engineering Science and Technology, Vol. 43, No. 1, 2008, pp. 46-53. doi.org/10.1179/174327807X214635

[25] S. L. Li, H. Y. Ma, S. B. Lei, R. Yu, S. H. Chen and D. X. Liu, "Inhibition of Copper Corrosion with Schiff Base Derived from 3-Methoxysalicylaldehyde and O-Phenyldiamine in Chloride Media," Corrosion, Vol. 54, No. 12, 1998, pp. 947-954. doi.org/10.5006/1.3284816

[26] K. Juttner, "Electrochemical Impedance Spectroscopy (EIS) of Corrosion Processes on Inhomogeneous Surfaces," Electrochimica Acta, Vol. 35, No. 10, 1990, pp. 1501-1508. doi.org/10.1016/0013-4686(90)80004-8

[27] A. A. El Hosary, R. M. Saleh, A. M. Shams and E. Din, "Corrosion Inhibition by Naturally Occurring Substances-I. The Effect of Hibiscus Subdariffa (Karkade) Extract on the Dissolution of $\mathrm{Al}$ and Zn," Corrosion Science, Vol. 12, No. 12, 1972, pp. 897-904. doi.org/10.1016/S0010-938X(72)80098-2

[28] F. Mansfeld, M. W. Kendig and W. J. Lorenz, "Corrosion Inhibition in Neutral, Aerated Media," Journal of the Electrochemical Society, Vol. 132, No. 2, 1985, pp. 290296. doi.org/10.1149/1.2113820

[29] X. Wu, H. Ma, S. Chen, Z. Xu and A. Sui, "General Equivalent Circuits for Faradaic Electrode Processes under Electrochemical Reaction Control," Journal of The Electrochemical Society, Vol. 146, No. 5, 1999, pp. 1847-1853. doi.org/10.1149/1.1391854

[30] M. S. Morad, "An Electrochemical Study on the Inhibiting Action of Some Organic Phosphonium Compounds on the Corrosion of Mild Steel in Aerated Acid Solutions," Corrosion Science, Vol. 42, No. 8, 2000, pp. 1307-1326. doi.org/10.1016/S0010-938X(99)00138-9

[31] G. Gunasekaran and L. R. Chauhan, "Eco Friendly Inhibitor for Corrosion Inhibition of Mild Steel in Phosphoric Acid Medium," Electrochimica Acta, Vol. 49, No. 25, 2004, pp. 4387-4395. doi.org/10.1016/j.electacta.2004.04.030

[32] W. Scheider, "Theory of the Frequency Dispersion of Electrode Polarization. Topology of Networks with Fractional Power Frequency Dependence," The Journal of Physical Chemistry, Vol. 79, No. 2, 1975, pp. 127-136. doi.org/10.1021/j100569a008

[33] H. Ma, S. Chen, X. Chen, G. Li and X. Yang, "Analysis of Impedance Data with Dispersing Effect by Using the Linear Least Squares Regression Method," Journal of Serbian Chemical Society, Vol. 62, No. 12, 1997, pp. 12011212.

[34] D. D. MacDonald and M. C. H. Mckubre, "Modern Aspects of Electrochemistry," Plenum Press, New York, 1982.

[35] M. Touzet, M. Cid, M. Puiggali and M. C. Petit, "An EIS Study and Auger Analysis on 304L Stainless Steel in Hot Chloride Media before and after a Sample Straining," 
Corrosion Science, Vol. 34, No. 7, 1993, pp. 1187-1196. doi.org/10.1016/0010-938X(93)90297-T

[36] O. Olivares-Xometl, N. V. Likhanova, R. Martinez-Palou and M. A. Dominguez-Aguilar, "Electrochemistry and XPS Study of an Imidazoline as Corrosion Inhibitor of Mild Steel in an Acidic Environment," Materials and Corrosion, Vol. 60, No. 1, 2009, pp. 14-21. doi.org/10.1002/maco.200805044

[37] A. Alagta, I. Felhosi, J. Telegdi, I. Bertoti and E. Kalman, "Effect of Metal Ions on Corrosion Inhibition of Pimeloyl-1,5-Dihydroxamic Acid for Steel in Neutral Solution," Corrosion Science, Vol. 49, No. 6, 2007, pp. 2754-2766. doi.org/10.1016/j.corsci.2006.11.008

[38] K. F. Khaled, "The Inhibition of Benzimidazole Derivatives on Corrosion of Iron in $1 \mathrm{M} \mathrm{HCl}$ Solutions," Electrochimica Acta, Vol. 48, No. 17, 2003, pp. 2493-2503. doi.org/10.1016/S0013-4686(03)00291-3

[39] K. Babic-Samardzija, C. Lupu, N. Hackerman, A. R. Barron and A. Luttge, "Inhibitive Properties and Surface morphology of a Group of Heterocyclic Diazoles as Inhibitors for Acidic Iron Corrosion," Langmuir, Vol. 21, No. 26, 2005, pp. 12187-12196. doi.org/10.1021/la0517661

[40] E. Machnikova, K. H. Whitmire and N. Hackerman, "Corrosion Inhibition of Carbon Steel in Hydrochloric Acid by Furan Derivatives," Electrochimica Acta, Vol. 53, No. 20, 2008, pp. 6024-6032. doi.org/10.1016/i.electacta.2008.03.021

[41] C. T. Wang, S. H. Chen, H. Y. Ma and N. X. Wang, "Study of the Stability of Self-Assembled N-Vinylcarbazole Monolayers to Protect Copper against Corrosion," Journal of Serbian Chemical Society, Vol. 67, No. 10, 2002, pp. 685-696.

[42] J. F. Moulder, W. F. Stickle, P. E. Sobol and K. D. Bamben, "Handbook of X-Ray Photoelectron Spectroscopy: A Reference Book of Standard Spectra for Identification and Interpretation of XPS Data," Physical Electronics Division, Eden Prairie, 1995.

[43] E. Kalman, F. H. Karman, I. Cserny, L. Kover, J. Telegdi and D. Varga, "The Effect of Calcium Ions on the Adsorption of Phosphonic Acid: A Comparative Investigation with Emphasis on Surface Analytical Methods," Electrochimica Acta, Vol. 39, No. 8-9, 1994, pp. 11791182. doi.org/10.1016/0013-4686(94)E0034-W

[44] N. S. McIntyre and D. G. Zetaruk, "X-Ray Photoelectron Spectroscopic Studies of Iron Oxides," Analytical Chemistry, Vol. 49, No. 11, 1977, pp. 1521-1529. doi.org/10.1021/ac50019a016

[45] S. Maroie, M. Savy and J. J. Verbist, "ESCA and EPR Studies of Monomer, Dimer, and Polymer Iron Phthalocyanines: Involvements for the Electrocatalysis of Molecular Oxygen Reduction," Inorganic Chemistry, Vol. 18, No. 9, 1979, pp. 2560-2567. doi.org/10.1021/ic50199a046

[46] K. Asami, K. Hashimoto and S. Shimodaira, "X-Ray Photoelectron Spectrum of $\mathrm{Fe}^{2+}$ State in Iron Oxides," Corrosion Science, Vol. 16, No. 1, 1976, pp. 35-45. doi.org/10.1016/S0010-938X(76)80005-4
[47] M. Koudelka, J. Sanchez and J. Augustynski, "On the Nature of Surface Films Formed on Iron in Aggressive and Inhibiting Polyphosphate Solutions," Journal of The Electrochemical Society, Vol. 129, No. 6, 1982, pp. 11861191. doi.org/10.1149/1.2124084

[48] N. Nakayama, "Inhibitory Effects of Nitrilotris-(Methylenephosphonic Acid) on Cathodic Reactions of Steels in Saturated $\mathrm{Ca}(\mathrm{OH})_{2}$ Solutions," Corrosion Science, Vol. 42, No. 11, 2000, pp. 1897-1920. doi.org/10.1016/S0010-938X(00)00034-2

[49] N. Ochoa, G. Baril, F. Moran and N. Pebere, "Study of the Properties of a Multi-Component Inhibitor Used for Water Treatment in Cooling Circuits," Journal of Applied Electrochemistry, Vol. 32, No. 5, 2002, pp. 497-504. doi.org/10.1023/A:1016500722497

[50] M. El Azhar, M. Traisnel, B. Mernari, L. Gengembre, F. Bentiss and M. Lagrenee, "Electrochemical and XPS Studies of 2,5-Bis(N-Pyridyl)1,3,4-Thiadiazoles Adsorption on Mild Steel in Perchloric Acid Solution," Applied Surface Science, Vol. 185, No. 3-4, 2002, pp. 197-205. doi.org/10.1016/S0169-4332(01)00650-X

[51] A. Meneguzzi, C. A. Ferreira, M. C. Pham, M. Delamar and P. C. Lacaze, "Electrochemical Synthesis and Characterization of Poly(5-Amino-1-Naphthol) on Mild Steel Electrodes for Corrosion Protection," Electrochimica Acta, Vol. 44, No. 12, 1999, pp. 2149-2156. doi.org/10.1016/S0013-4686(98)00323-5

[52] G. P. Cicileo, B. M. Rosales, F. E. Varela and J. R. Vilche, "Comparative Study of Organic Inhibitors of Copper Corrosion," Corrosion Science, Vol. 41, No. 7, 1999, pp. 1359-1375. doi.org/10.1016/S0010-938X(98)00190-5

[53] K. Aramaki and T. Shimura, "Prevention of Passive Film Breakdown on Iron in a Borate Buffer Solution Containning Chloride Ion by Coverage with a Self-Assembled Monolayer of Hexadecanoate Ion," Corrosion Science, Vol. 45, No. 11, 2003, pp. 2639-2655. doi.org/10.1016/S0010-938X(03)00071-4

[54] F. H. Karman, I. Felhosi, E. Kalman, I. Cserny and L. Kover, "The Role of Oxide Layer Formation during Corrosion Inhibition of Mild Steel in Neutral Aqueous Media," Electrochimica Acta, Vol. 43, No. 1-2, 1998, pp. 69-75. doi.org/10.1016/S0013-4686(97)00236-3

[55] J. L. Fang, Y. Li, X. R. Ye, Z. W. Wang and Q. Liu, "Passive Films and Corrosion Protection due to Phosphonic Acid Inhibitors," Corrosion, Vol. 49, No. 4, 1993, pp. 266-271. doi.org/10.5006/1.3316048

[56] K. Aramaki, "Preparation of Self-Healing Protective Films on a Zinc Electrode Treated in a Cerium(III) Nitrate Solution and Modified with Sodium Phosphate and Cerium(III) Nitrate," Corrosion Science, Vol. 46, No. 6, 2004, pp. 1565-1579. doi.org/10.1016/j.corsci.2003.09.030

[57] X. H. To, N. Pebere, N. Pelaprat, B. Boutevin and Y. Hervaud, "A Corrosion-Protective Film Formed on a Carbon Steel by an Organic Phosphonate," Corrosion Science, Vol. 39, No. 10-11, 1997, pp. 1925-1934. doi.org/10.1016/S0010-938X(97)00086-3

[58] H. Amar, T. Braisaz, D. Villemin and B. Moreau, "Thio- 
morpholin-4-Ylmethyl-Phosphonic Acid and Morpholin4-Methyl-Phosphonic acid as Corrosion Inhibitors for Carbon Steel in Natural Seawater," Materials Chemistry and Physics, Vol. 110, No. 1, 2008, pp. 1-6. doi.org/10.1016/j.matchemphys.2007.10.001

[59] R. O. Carter, C. A. Gierczak and R. A. Dickie, "The Chemical Interaction of Organic Materials with Metal Substrates. Part II: FT-IR Studies of Organic Phosphate Films on Steel," Applied Spectroscopy, Vol. 40, No. 5, 1986, pp. 649-655. doi.org/10.1366/0003702864508656

[60] I. Sekine and Y. Hirakawa, "Effect of 1-Hydroxyethylidene-1,1-Diphosphonic Acid on the Corrosion of SS 41 Steel in $0.3 \%$ Sodium Chloride Solution," Corrosion, Vol. 42, No. 5, 1986, pp. 272-277. doi.org/10.5006/1.3584904

[61] G. Gunasekaran, N. Palaniswamy, B. V. A. Rao and V. S. Muralidharan, "Synergistic Inhibition in Low Chloride Media," Electrochimica Acta, Vol. 42, No. 9, 1997, pp. 1427-1434. doi.org/10.1016/S0013-4686(96)00366-0

[62] S. Yu and G. M. Chow, "Carboxyl Group (- $\left.\mathrm{CO}_{2} \mathrm{H}\right)$ Functionalized Ferromagnetic Iron Oxide Nanoparticles for
Potential Bio-Applications," Journal of Materials Chemistry, Vol. 14, 2004, pp. 2781-2786. doi.org/10.1039/b404964k

[63] L. J. Bellamy, "Advances in Infrared Group Frequencies," Chaucer Press Ltd., Auckland, 1968.

[64] J-G. Mao and A. Clearfield, "Metal Carboxylate-Phosphonate Hybrid Layered Compounds: Synthesis and Single Crystal Structures of Novel Divalent Metal Complexes with N-(Phosphonomethyl)Iminodiacetic Acid," Inorganic Chemistry, Vol. 41, No. 9, 2002, pp. 2319-2324. doi.org/10.1021/ic011094w

[65] Y. I. Kuznetsov, Proceedings of the European Corrosion Congress (EUROCORR 2003), Budapest, 2003, p. 320.

[66] A. J. Freedman, "Cooling Water Technology in the 1980s," Materials Performance, Vol. 23, No. 11, 1984, pp. 9-16.

[67] V. Deluchat, J.-C. Bollinger, B. Serpaud and C. Caullet, "Divalent Cations Speciation with Three Phosphonate Ligands in the pH-Range of Natural Waters," Talanta, Vol. 44, No. 5, 1997, pp. 897-907. doi.org/10.1016/S0039-9140(96)02136-4. 